\title{
Shifting clinical relevance from 'what is the matter to what matters' utilising Legitimation Code Theory. A comparative investigation of medical students' social accountability perceptions.
}

Kingsley James Whittenbury ( $\nabla$ kingsley.whittenbury@gmail.com )

Flinders University

\section{Research Article}

Keywords: Sociological imagination, health equity, social equity identity, critical reflexivity, regulative discourse, recontextualization, curricular justice, knowledge management system, Legitimation Code Theory, biosemiotics.

Posted Date: February 21st, 2022

DOI: https://doi.org/10.21203/rs.3.rs-1118537/v1

License: (c) (1) This work is licensed under a Creative Commons Attribution 4.0 International License. Read Full License 


\section{Abstract}

Pedagogy for socially accountable medical professionalism lacks systematic integration of relevant social and biomedical facts. A sociological gaze and change in medical discourse may be transformative. A mixed methods study compared perceptions of social justice in healthcare of forty medical student participants from diverse social positions enrolled in two Australian medical schools. The 'capability to aspire' to prosocial professionalism links Sen's capability theory and Bourdieu's theory of practice to compare outsiders and insiders in a traditional and a socially accountable program. Comparison of First and Final Year cohorts aimed to identify the regulative discourses of each program. Demographic, short answer and multi-choice questions, and semi-structured audio-recorded interview tested participants' aspirations, knowledges and reasoning related to social accountability.

All cohorts supported social justice learning and agreed Indigenous, refugee and migrant groups were most disadvantaged in Australian health care. Final Year participants had greater awareness of health system shortfalls in social accountability, citing professional discourses lacking equity awareness, unfair patient responsibilisation, system overload and mismatch to Indigenous health needs. Less intention to practice in areas of health need was shown by participants with zero and multiple devalorised social identities than those with single equity identities. A common finding was inability to modify clinical reasoning to recognise what matters for equity needs, making 'health equity' a threshold concept. Critical reflexivity on human contexts of illness production was best realised by outsiders, unrelated to program. International participants held stronger perceptions of mismatch between the Australian health system and Indigenous health needs. Results inform a socio-science approach to learning health equity that builds on students' prosocial values, social identities, and meaning-making of social contexts. A recontextualising principle to validate health equity perspectives in medical pedagogy, and knowledge management system to integrate social and medical discourses, are proposed. The potential benefits of biosemiotic, edusemiotic and semioethic approaches to the humanising turn in medical education are discussed. Legitimation Code Theory provides a means to systematise diverse discourses in medical education. Biosemiotic concepts of lifeworld and dialogical communication may further cultivate students' sociological and moral imagination of health production, and creativity for socially accountable solutions to emergent illness.

\section{Background}

The medical graduates who lead the culture of medicine toward a more humanistic, patient-centred, and socially accountable professionalism will need to possess a paradigm of care and justice cognizant of how complex global societal changes impact on patients' lives [1]. A wish-list of medical education reforms for the new millennium recognised needs in relation to changed global social contexts of health [2]. In 2002, release of The Charter on Medical Professionalism [3] ('A Physician's Charter') required physicians to contribute to the welfare of local and global peoples, a duty of social accountability. 
The implications for medical education of the millennial economy of human health were appraised, and lead reformers called for a new consciousness to guide its evolution [4]. Critical consciousness of the dynamic, societal locus of health production implicates equity or fairness as the 'central organising principle' [5]. Embodied and situated learning may be transformative of stance to social justice [6] and draws critical attention to the social identities and aspirations of outsider medical students from the 'widening participation agenda', many first-in-family in higher education [7]. The agenda aimed to ensure greater fairness in patient access to services, to promote equity of health outcomes, and render medical education more inclusive [8]. Yet, professional capabilities (moral, ontological, and epistemological) for socially accountable praxis; and a suitable pedagogy for integrating quantitative medical and qualitative social science discourses; require elaboration [9]. Rising inequalities in the distribution of primary health services and health care outcomes coincide with global ecosocial crises and disruption of $20 \mathrm{C}$ 'modern era' societal norms, making populations more vulnerable to distress and chronic illness [10]. How patients respond to factors shaping their social world is the subject of social semiotics. Embodied signs in individuals of "social mechanisms that shape meaning-making" [11], brings semiotics to the attention of clinical educators.

Two Australia medical schools provided a ready comparison of program ethos; School A having a traditional biomedical research program, and School B claiming a social justice provenance. A mixed methods study sought the perceptions of millennial era medical students of the social accountability skills essential to their imminent practice as physicians. The freedom 'to do and to be' their prosocial selves, was held in relation to curricular justice to participants' social identities, chosen medical program, and preferred career trajectory. The study was guided by 'A Physician's Charter' [12] and evidence of the 'new public health' $[13,14]$ noting growing social, commercial, and cultural inequalities in societies as dominant drivers of iniquitous health outcomes.

\section{Introduction}

'A Physician's Charter' prioritised education of social accountability in health care, and actions of social justice in health care and health improvement. Professional responsibility requires re-envisioning the task of psycho-social history-taking; to see the patient in broader perspective [15] and to narrow the social distance between physicians and patients $[16,17]$.

Medical educators are urged to inculcate a sociological imagination of health to counter the dominance of the biomedical paradigm [18]. The Charter aimed to instil greater humanism to the culture of medicine; and for students to recognise the societal conditions from which health emerges. Under the biomedical gaze, the significance of patients' societal contexts in generating and modifying health outcomes was under-valued. Patients' social contexts were considered unchangeable; or objectified and 'medicalised' to fit the medical worldview [19]. Social accountability practices resolve to improve health outcomes of patients with lives disadvantaged by distressing and unjust social circumstances. A more ethical, sustainable professionalism may then stabilise. 
As medical students, study participants were future physicians, variably situated in relation to Australian and global societies in the post-modern era. 'Insider' students were those with capital assets and networks that advantage a 'feel for the game' of medical professionalism [20]. 'Outsiders' are capable students with few connexions to medical culture, and lacking preparation for the 'rules of the game' that can ensure success in the professional field. The rules of 'the biomedical game' evolved during the past century to value highly specialised and costly expertise in reductionist, organ-centred medicine and surgery. A powerful pharmaceutical and technological industry has prospered from the mechanistic, molecular approach of the biosciences, commodified as 'evidence' [21]. The dominance of biopharmaceutical science occurred despite Flexner's reforms 100 years earlier introducing systems thinking to medical education [22].

Change in professionalism is theorised to result from the interaction of diverse student discourses [23]; and Bourdieu's theory of practice suggests social justice motivations are intrinsic dispositions of students with personal and family experiences of injustice. These dispositions shape and empower the working model, termed habitus, by which a student perceives the world [24]. Widening participation reforms promote entry to medicine of students typical of current social diversity: urban multicultural, Indigenous, low SES, and rural populations. The reforms reflect concerns for achieving national and global targets of health equity [25]. While the type of professionalism medical students aspire to can vary during training, for students oriented to social justice, primary health care is the optimal choice. Yet, loss of idealism between the First and Final Years [26], and growing financial pressures, can mean that students' choices become more pragmatic [27].

Transformative culture change to a new professionalism may require graduates exercise novel skills that critique and close gaps in health service outcomes exposed in orthodox medicine [28]. As 'becoming' physicians in an age of uncertainty, contemporary medical students are future facing and may be better placed to view the adjacent possible [29] in the complexity of global societal changes. The study sought

to investigate diverse medical students' critical dispositions, perceptions, discourses, knowledges, equity consciousness, and reasoning of health-related needs in Australian and global health contexts.

\section{Theorising social health practice in medical professions education}

Medical education research has investigated factors that could maximise the practice potentials of diverse students entering medicine. Without well-defined supports, students from social positions "that match what societies need" [30] can struggle to adjust to hidden assumptions in the structural conditions of training. Brosnan [31] applied Bourdieu's notion of 'field' to medical education, conducting a comparative analysis of a traditional and an innovative medical school in the UK. Results suggest schools need to be reflexive of how they differentiate the ethos of their program and signify market appeal. A need for equity actions by medical schools was recognised, to activate the latent ethical capitals outsider students bring to the field [32]. These can otherwise become lost to conforming forces of curricula and socialisation. One study showed caring for the underserved was no more likely among students with religious beliefs [33]. Community based clinical experiences can provide students 
opportunities for inquiry into diverse human contexts of illness [34]. Yet, retention of humanist values in an 'evidence-based' science program may rely on student socialisation in service-learning programs and extra-curricular student-led associations.

Viewed empathetically and critically, situated learning in communities of practice [35] can provide students novel ways of 'seeing' and understanding how health and illness are produced. For some however, experiences of human disadvantage can trigger aversion or "fear of getting too close to need' [36]. In accord with 'control-value theory' educators are urged to create the conditions, as simulations, for students to subjectively "experience control and exercise personal agency" [37] in situations of social health learning. Yet, students learn early in their training about the need for self-care related to the high incidence of physician overwork and mental distress [38]. This awareness may induce meta-reflexivity on choice of career paths: the exercise of personal morality to achieve an aesthetic whole, combining personal and career goals [39]. Time for self-restoration, nurturing relationships or raising a family need to be self-managed. Yet, proximity to social adversity endows students from socially deprived settings 'funds of knowledge' of social existence [40]. They are described as 'born knowers' [41] of local sociopolitical geographies impacting health (Fig. 1).

A change in physician 'gaze' to perceive a sociological healthscape suggests the need for critical consciousness [42] of diverse health needs, and a prosocial moral compass. The shift in practice from health demands to health needs places an integrative focus on health care and health improvement; a way of 'reading the world' to make meaning, and formulate reasoned actions adjusted for social inequities. Critical consciousness can be understood as "the capacity to 'problematize' the natural, cultural and historical reality in which one is immersed" [43]. In the context of $21 \mathrm{C}$ medicine this ought to include critical scrutiny of the profession itself. The critical, sociological gaze of critical consciousness confers a moral critique of ways social systems are structured to benefit few in society while disadvantaging many. Social injustice results when powerful social, political, and commercial forces unfairly diminish the power and autonomy of citizens to shape healthy conditions for living and raising families [44]. When internalised, inequity of social worth can produce distress; and when unremitting, long standing, and intergenerational illness. Stigma can also induce critical consciousness for the consequences for others' stigma experiences, including self-stigma and coping strategies [45].

A critical perspective that problematizes the holistic circumstances of health production 'takes into account' power relations between the patient's bespoke needs and capabilities, and systemic constraints. The constraints identified by the 'new public health' [46] flow from organisation of social, political, and commercial constraints in both global and local contexts. As 'causes of the causes' of population health, constraints on the conditions of living account for over $70 \%$ of poor health outcomes [47]. The biomedical paradigm of science is bound within human bodies; yet recursive feedback controls on internal homeostasis by human distress respond to external ecosocial contexts and extend both 'downward' to genes and 'upward' to emergent physical effects [48]. Context can include the disempowered social position of patients with devalorised identities, which for a majority of First Nations or Indigenous peoples stems from historical colonial injustices. 
The social sign-world of human marginalisation, or stigma, refers to a semiotic process. Semiotics is the study of signs of all kinds; and semantics, the subconscious interpretation of signs to make meaning. Through the senses, the human mind-body (or psycho-soma) communicates with signs in the lifeworld [49]; to contemporise meaning and adapt to changing circumstances. Such 'dialogical' communication and meaningful interpretation of social (dis)harmony is captured in the biosemiotic paradigm of health and illness [50, 51].

\section{Communication as health sign production and meaning making}

Perceptions of distress resulting from social inequity are conveyed by the senses and interpreted as negative schema in cognitive and memory regions of the brain [52]. In a biosemiotic reading, adverse signs in an individual's lifeworld, constrain freedom. Signs, and biosemiosis - the study of signs of life, extend from the micro level of atomic interactions to macro relations in society [53]. A sign is information or data that requires interpretation to make adaptive meaning to the organism [54]. When hot weather is sensed, for example, somatic meanings include thirst and shade-seeking actions to maintain internal homeostasis within vital limits. Yet, an overlay of social, political, and commercial signs communicates constraints to lifeworld freedoms, acting downward in a non-linear manner on organ systems [55]. Similarly, stressful experiences in early childhood that produce adult illness follow the epigenetic, nonlinear pattern of complex adaptive systems (CAS) [56]. The linear causation of Newton's mechanistic physics does not predict the outcomes of systems of systems [57]. Instead, predictable variation in homeostatic responses and behaviours in relation to local conditions emerge at the population level.

Implications of this communication model of illness extend to medical education of patient-centred care. When social, financial, or policy-related stressors persist, the protracted stress response alters gene expression, and chronic illness eventuates. In a biosemiotic paradigm, the term 'non-communicable' disease is a misnomer. Signs of threat to harmonious living conditions from ecosystem or lifeworld adversity, dialogically communicate meaning as poor mental and physical health outcomes [58]. Conversely, advantageous social conditions that underpin socio-economic status (SES) communicate health meanings; embodied as the 'capability to act' in one's own best interests [59]. Here, non-material relations across levels of systems; not biochemical material relations; are the causes of illness.

\section{Theoretical frame for comparing professional discourses}

In this study, a medical student's capability to practice a preferred type of professionalism was underpinned by Sen's capability theory and supplemented by Bourdieu's social theory of practice. Studies of the French higher education system by Pierre Bourdieu showed how augmentation of power through education [60] reproduced existing social hierarchies. The unfair ordering of human worth hierarchies model to human perceptions, and to internal conversations, may be fundamental to understanding unequitable health outcomes [61].

In recognition of inequalities between insider and outsider status among medical students, Bourdieu's theory of practice and Sen's capability theory were combined to conceptualise participants' capability to 
aspire [62] to a preferred 'type of medical professionalism' [63] (see Fig. 2). The participant's capability as social change agent was also held in relation to the regulative discourse [64] of their school's program. School B has a graduate entry program and belongs to a network of socially accountable medical schools. School A has a traditional secondary entry program directing graduates to general practice and specialist careers.

\section{Theorising medical students' social accountability capabilities}

Traditional medical programs can place pressure on a student's primary habitus to adapt to the norms of the professional culture. Conformity in dress, speech, knowledge, clinical skills, and public behaviours models a narrow, bourgeois socialisation process [65]. There are limited ways of standing out in medical culture that respect students' primary habitus. The risk for outsider students is fractured habitus [66] incomplete transformation to the norms of professionalism - and greater cynicism for the medical project. The added emotion work of 'fitting in' can take a toll on the physicians' health [67]. In summary, legitimation of social accountability and social knowers in medical education may reduce the wastage of prosocial dispositions that outsiders bring to patient care.

Maton [68] analysed standpoint theory that argues social gazes can be grouped by proximity to social reality (Figure 1, below); but found the strength of gaze depends on how strongly bounded and controlled the categories are.

An individual's relation to social knowledge is not reducible to the knower, but more reasonably reflects a 'dialogical transaction' between subjective and objective reality [68]. This dialogue between agents and structures can be abstracted as a sign communication process. Communication occurs between 'signs perceived' and 'meanings interpreted' from each person's unique lifeworld: the sign world produced by the ways society is organised or 'structured' [69]. Learning from experience is a process of reading signs and becoming 'other' [70]: a specialist and moral knower.

This 'biosemiotic' paradigm regards sign-following a basic process of all life [71]; and lifeworld the modelling system or "world of meaning and sensory engagement that the organism is engaged in" [72]. Signs of threat to social freedoms that produce wellbeing are common perceptions among people with devalorised social identities [73]; and to others made vulnerable by adverse social determinants of health. A useful term for the complex semiotic meaning-making process 'between the normal and the pathological' is the 'social health-illness dialectic' [74]. It suggests "society should promote health through individual and social means" (ibid) and recognises the health significance of maldistributed power in societies. Survey and interview questions in the study aimed to elicit the dialogical grammar bridging individual and societal structures [75] in participants' discourses; syntax that may inform an integrated socio-science pedagogy for socially accountable practice.

Likewise, stigma and self-stigma among medical students entering an intolerant medical culture may reduce their 'capability to aspire' to a career path that may include social health practices. To identify proximity to social injustice, participant 'gaze' was classified on the basis of having a single equity 
identity (e.g., female gender); two or more equity identities (e.g., female, black, and LGBQTI sexuality) called intersectionality; and non-equity identity. Citizens with intersectional equity identities can experience social constraints on each marginalised identity [76] and adverse social circumstance in their lives. Intersectional medical students, many from non-professional backgrounds, can have reduced capability to advance in the dominant medical culture; yet may have valuable knowledges and insights to social inequity and stronger orientations to social justice. Lack of curricular justice [77] permitting diverse voices and aspirations to be heard, may be expected in discourses of Final Year outsider students enrolled in program A. Success of the regulative discourse of social accountability in program B may be revealed by Final Year outsiders. However, an unreflexive 'hidden curriculum' in medicine [78] can devalorise marginalised patient (and student) identities and transmit mismatched practices between biomedical systems and patients' objective health needs [79]. Bourdieu \& Wacquant (1992) termed uncritical assumptions coded in higher education discourses, misrecognitions [80].

Curricular justice may be crucial to development of diverse medical students' aspirations 'to make a difference' and fulfil vocations for holistic health care practice. Attractively, curricular legitimation of social justice practices may provide 'bridging capital' for these students; and mobilise "the potential for subversion and contestation of normative professionalism" [81].

Medical educators investigating the support needs of outsider medical students have sought to understand the structural constraints on retention and success through to graduation. Critical social theories, as Bourdieu's theory of practice, can help educators make sense of challenges outsider students face in a hidden curriculum that regulates the medical culture [82]. The requirement for social accountability may however advantage outsider students. Yet, a mixed methods study of Australian medical students showed students with a single equity identity were more likely to choose practice in underserved populations than those with intersectional identities [83].

\section{Methods}

\section{Study Aims}

The study aimed to demonstrate the characteristics of medical students volunteering for a study of their perceptions of the value of social justice to medical practice. Selection of two urban medical schools enabled comparison of the declared regulative principles [84] guiding recruitment and program design. School A touts a traditional medical program, School B, social accountability. Only First and Final Year students were invited to participate, to compare curriculum effects between the preclinical and clinical phases of each course. Comparisons of participants' demographic and social equity identity features aimed to identify the capital assets of habitus that distinguish insider from outsider status to the medical profession. Preferred 'type of medical professionalism' [85] was surveyed to indicate participants' aspirations for a particular career path.

\section{Study Design}


Study recruitment notices posted on school intranets targeted First and Final Year students, seeking their 'views of social justice in health care and health production'. A certificate of appreciation and a food voucher were offered for participation. A total of ten participants from each cohort was deemed a satisfactory sample size for reliable results but required recruitment over the two years 2013-14. A total of forty students were finally recruited, with numbers in each cohort as follows; First Year School A- 6; Final Year School A - 12; First Year School B -13; Final Year School B - 5.

The mixed methods inquiry posed six research questions of relevance to pedagogy for the continuing professional development of social accountability.

1. How do medical student participants, of diverse social backgrounds and identities, critically interpret the value of social justice to medical practice?

2. What fault lines do participants perceive in current medical professional practices and how do these inform medical education of social accountability?

3. What are the characteristics of participants having a 'sociological imagination' of health?

4. How do participants' social equity identities relate to aspiration for prosocial practice?

5. How does transformation to a social justice perspective of professional responsibilities take place; and what impacts can be attributed to medical programs (A cf. B) and curricula (Final cf. First Year)?

6. Which axiologies (habitus/ stance), epistemologies (system knowledges) and ontologies (ways of becoming a professional or choice of type of professionalism) enable participants to integrate social and biological knowledges into a holistic phronesis?

All methods were carried out in accordance with ethical guidelines for research with humans set by Flinders Social and Behavioural Research Ethics Committee (Approval \#6877). The study was designed to introduce participants to the professional duty of social accountability; first, by reference to the 2002 Charter of Medical Professionalism (see box below) [86]; and second, employing the grammar of social justice in initial survey questions to prepare a mindset for the semi-structured interview that followed. 


\title{
A Physician's Charter (ABIM Foundation 2002) [86]
}

\author{
Principle of Social Justice \\ The medical profession must promote justice in the health care system, \\ including the fair distribution of health care resources. Physicians should work \\ actively to eliminate discrimination in health care, whether based on race, \\ gender, socioeconomic status, ethnicity, religion, or any other social category.
}

At the time of the study, School A had a traditional six-year, secondary school entry medical program. School B had a four-year, post-graduate program. Both schools enrolled fee-paying international students; the majority from Asian nations, but also North America; and local students from 'outsider' backgrounds.

Four cohorts were obtained from First and Final Year participants at Schools A and B. Participant identity was coded by program (A or B), Year (1 or 4 / 6), and a pseudonym. School B participants' prior academic field and careers were recorded. Social demographics, equity identities, and type of professionalism were evaluated from demographic, survey and interview data and entered in a database. Themes analysed from transcribed interview data were triangulated with participant data (informing primary habitus) in participant vignettes [87] then compared to discourses of emerging secondary habitus (becoming a physician) among study cohorts.

In addition to undergraduate and postgraduate status, school program, Year group, and insider or outsider status, participants were categorised by social equity identities indexed by proximity to conditions of social inequity. These relations can confer 'knower' status related to participants' family experiences of injustice; as migrants or refugees; or social stigmatising of gender and sexuality, religion, disability, ethnicity, or poverty. The qualitative research concept habitus conveys the structuring of individuals' correspondence to a social field; driven by value dispositions related to family guidance and various 'capital' assets [88]. Powerful assets that high status applicants bring to medicine can include physicians in the family (cultural capital), high family income (financial capital), private education and social networks (social capital). Educational capital is the main cultural advantage of WP students. Absent 'curricular justice' [89] to support students' prosocial capabilities and aspirations, a competitive school culture can favourably legitimate the quantitative episteme ahead of students' qualitative values of justice and care. Recalling how higher education tends to reproduce the hierarchy of social positions, habitus is the set of career trajectories WP students can expect to achieve within the constraints of the medical culture. Participants preferred 'type of professionalism' was recorded in the study survey. 
Interview questions were formulated to test participants' problematising logic (critical reflexivity) on patients whose health is contextualised by external (social, economic, and commercial) determinants. All study questions and surveys were entered in SurveyMonkey for ease of data collection of multi-choice (MCQ) and short answer questions (SAQ); while interview responses were gathered by digital audiorecorder. For the convenience of this article, just two interview questions are discussed (Fig. 2).

All study questions were uploaded to $\AA$ SurveyMonkey, a familiar online research tool. An initial array of questions (MCQ and SAQ) drew on participants' ethical concerns for justice and care in medical professionalism; nomination of patient groups most disadvantaged in the Australian health care system; support for learning the relevance of social justice to medical practice; and demographic data for features of habitus, social equity identities, first-in-family and socio-economic status (SES). Personal information included participants' Australian State or country of origin; post-secondary or post-graduate education status; preferred 'type of medical professionalism'; and membership of prosocial groups within and external to medicine. Family capitals informing insider or outsider habitus included parents' careers, combined income, and home postcode. Parents' and siblings' highest education level informed first-infamily status and habitus.

The second question set, conducted as a semi-structured interview, sought participants' social health reasoning and knowledge sets; dispositions for forming critical perspectives of society; and learning contexts informing a sociological gaze of health inequity. As examples of this set, I outline below the purpose of structured interview questions testing for social accountability. These questions tested ability to problematise the health equity needs of marginalised groups and identities, framed in hypothetical clinical scenarios.

Questions were constructed to require abductive, not clinical logic of social health equity. Study Question 3. tested the logic of social accountability reasoning in relation to individuals and Question 7. in relation to a stigmatised group.

Question 3. problematised physician expectations of behaviour change using bioscientific evidence as the means of motivation, when no account is taken of how patients' lifeworld experiences distribute selfefficacy. The answer requires sociological gaze of difference in patients' capabilities to act in their own best interest (agency) given their vulnerability to (structural) constraints of social health determinants. Question 7. directed participant gaze to a stigmatised patient identity (a social inequity context) and asked them to reason why patients' social equity identities may be important to improving health care outcomes.

These questions aimed to evaluate navigation of the potential threshold concept [90] of equity as social accountable practice. The concept of distributive justice in health requires equitable access to resources for maintaining health in populations; while emancipatory justice requires enablements that help people overcome dis-empowering beliefs about their social expectations and human rights [91]. Oral evidence was also sought of sociological imagination and creativity in participants' perceptions of health production in Question 8. This asked participants to imagine, as a physician in a rural Australian town, 
how they may improve the health of residents. Perceptions of obstacles in their training limiting prosocial professionalism; and critical insights to social accountability needs gained from service- learning opportunities and student associations were also pursued.

The final set of survey questions (MCQ and SAQ) sought the relation between participants' social equity identities and agency for prosocial professionalism, retested knowledge of the social determinants of health, and validated participant reliability. Participants were invited to nominate their role models of social health justice.

\section{Study Setting}

Participants were met in their medical school and escorted to an interview room equipped with a computer and digital audio recorder operated by the investigator. Signed, informed consent was given before commencing a session. Participants entered answers to the first and third question sets into ®SurveyMonkey, while interview questions in the second set were answered orally and digitally audio recorded. The investigator transcribed interviews and conducted manual mixed methods data analysis, employing 'theory before' and 'theory after' qualitative methodology of Meyer \& Ward (2006) [92].

\section{Participants}

Participant characteristics of relevance to the study, apart from School and Year cohort, were; a. age; b. domestic / international; b. social equity identities; and c. insider / outsider status. First-in-family, low socio-economic status (SES), migrant or refugee background were features of outsiders. The number of prosocial student organisations a participant attended was regarded significant to their commitment to social justice. These data are collated in Table 1. (above). The previous career of School B participants was recorded to inform semi-structured interview questions. There is a predominance of outsiders, females, and single social equity identities. A social equity identity was assigned to females, those of migrant or refugee background, black or Indigenous ethnicity, LGBQTI sexuality, Muslim, Asian, low SES, rural or remote origin, and disabled. No participant declared Indigenous or disability status. Two participants voluntarily disclosed LGBQTI identities; a School A First Year participant (PA1) had four intersecting equity identities.

\section{Data analysis}

Interpretivist methodology applying the Meyer \& Ward 'theory driven' framework was first applied to the interview data, to extract themes; and then to the combined qualitative and quantitative data scripted as participant vignettes. 'Theory before' contained a moral frame, Rawls' 'social justice as fairness' [93]; an empowerment frame (Bourdieu's forms of capital); and an agency frame (Sen's capabilitytheory). An index of the themes and subthemes derived from initial analysis is listed in Figure 6 (below).

Reworking the data into participant vignettes, and subsequent grouping of vignettes into similar and dissimilar categories, allowed the investigator to view ethical differences across School A and School B curricula and programs; genders; equity identities; habitus; and domestic and international status. 
Vignettes allowed comparison of Year groups, social equity identities, and preferred 'of medical professionalism' [94]. Vignettes, like brief biographies, invite readers to co-interpret, make meaning, and validate analysis [95]. The collective bricolage effect of a vignette arrangement of mixed methods data can provide for "a thick, complex interpretation" [96] of the research question. Continuous comparative analysis [97] applied to study data produced categories and prepositions of discourses [98]; to formulate a 'theory after' analysis, following the Meyer \& Ward [99] qualitative method.

\section{Results}

\section{A. Participant habitus and aspiration for prosocial professionalism}

1. An international participant at School B gave poor responses and was excluded from the study. The remaining total was 39 participants: 19 from School A and 20 from School B.

2. More females volunteered for the study than males. The objective female to male gender ratio was 12:7 (School A) and 12:9 (School B). A First Year outsider at School A self-identified as gender fluid.

3. Based on demographic and interview data, School B cohorts had a higher proportion of students of outsider habitus compared to School A (2.5 to 1.1).

4. Participants' equity identities, social health knowledges, and intentions for prosocial practice were asymmetrical. Specifically, those with single equity identities indicated higher preference for practice in an underserved community than those with nil, or two or more (intersectional) identities (Figure 4). This result mirrors those of Griffin, Porteli \& Hu (2017) of lower intentions to work in underserved areas of medical practice among students of low and high SES at an urban Australian medical school.

5. No insiders chose professionalism Type G. (Practice in an area of need); a prediction of Bourdieu's theory of practice. Preferred 'type of professionalism' was distributed by social equity identities, not by Year level or medical program. 'Outsiders' at School B were more likely to choose Type F. professionalism (Follow your own morality. What works for you.) and Type G. (Practice in an area of need).

\section{B. School and Year cohorts and prosocial professionalism}

1. There was unanimous support for the learning of social justice in medical education.

2. There was agreement among all Year cohorts of the groups most disadvantaged in Australian health care: Indigenous, refugees and migrants. Participants witnessed the same racism, sexism and poverty shaming in health care as found in Australian society.

3. School A First Year participants, the youngest cohort, more often reported recent developmental awareness of abstract social justice concepts. More concrete concerns for local, national, and global health injustices were voiced by School B cohorts (Fig 5, below). Several participants of Asian background (at both schools) reported personal or family experiences of racism. 
4. The private-public gap in health care quality was regarded unfair by First Year Chinese participants in School B; and Chinese medicine proposed an alternative to western medicine for Indigenous health care.

5. Just one (School B, Final Year male) participant referred to historical ethical failures of professionalism.

6. Role models of social justice clustered into categories of personally known, professionals and prosocial celebrities or religious figures.

\section{Discourse themes}

The diversity of discourses for understanding social accountability in medical practice are listed in Fig. 5 and outlined in more detail, below.

\section{Theme 1. Critiques of medical professionalism}

Most critiques of medical professionalism were made by Final Year participants reflecting on training experiences in the health system. First Years drew on personal and service-learning experiences for their responses. Yet, the most trenchant critiques of 'the rules of the game' of medical professionalism was made by School A First Year (PA1); the participant with the highest intersectionality of equity identities. PA1 reported personal observations of the mistreatment of LGBQTI patients in the Singapore health system; and physician attitudes resembling legal not social justice, to pressing health needs of low SES families, citizens with addictions, and residents of a chronic care psychiatric facility. She understood how these misrecognitions, in the manner of complex adaptive systems theory (CAS), could worsen the health prospects of these groups.

Participant vignettes revealed several 'code clashes' between medical professionalism and social health contexts. Final Year cohorts voiced concerns about the following contemporary biomedical practices.

a. the hegemony of pharmaceutical treatments as the ultimate 'answer' in clinical care.

b. a silent curriculum that labels patients with low social capital and disputed hospital status 'acopics'; the result of inadequate funding of community-based disability care.

c. the irony of 'getting rid of patients' [100] with no sustainable solution for preventing their recycling through hospitals nor prevention of their chronic illnesses.

d. scepticism about political distribution of public health system funding.

e. anguish related to reduced opportunities and time for patient-centred care.

f. dismay at physician jargon conveying outmoded colonial attitudes (hierarchy, sexism, racism, ageism, poverty shaming) and victim blaming for addictions. 
g. deception about the true nature of health production by poverty and social conflicts by proximal risk factor and behavioural approaches that unfairly responsibilize patients.

h. the neutralizing of equity differences between patients [101]; a form of knowledge blindness.

The resulting professional consciousness reflects what Savransky \& Rosengarten (2014) refer to as 'what was excluded by what was taught' [102]. A First Year female at School B vented discontent: "They teach us about the social determinants of health, but not what to do about them." Time required for medical care protocols can represent loss of active student learning of patient-centred care needs [103].

\section{Theme 2. Transformation to a justice mindset}

Understood as a transformative learning process, discourses of social accountability were grouped in sequence 'from informative, to formative, to transformative' [104].

a. Insider participants were informed about social health inequity in secondary education, and in medical student organisations which directed charity to resourcing disadvantaged (e.g. Indigenous) groups. A Final Year female at School B, and Law graduate, was a leading student advocate for human rights and climate action. She held policy makers and funders of health-related systems ultimately responsible for distributive inequalities. A Final Year male at School A with high status parents, spoke of his mothers' prosocial work, table talk of social justice issues, and habit of keeping informed of sociopolitical events. Notwithstanding the family's high status, it was anathema to be thought uncaring of others' misfortunes. Few insiders referred to close professional experiences of the social adversities patients faced.

Another School A international and Final Year male watched a video of a woman having pseudo-seizures and felt contempt for her 'faking' a 'medical' illness. He later realised the error of applying biomedical criteria to a functional mental illness. Yet he was surprised by interview Question 5. comparing impacts of medicine and sociopolitical health advances. ['In the U.S. since 1950, only 3 out of seven years of improved life expectancy can be attributed to improvements in medicine.' What does this statistic suggest to you?]

b. Outsider participants referred to family experiences of social adversity as refugees and migrants to Australia that informed singular perceptions of social injustice. Many had intersectional equity identities and were ambitious to restore their families' capital status. Two School A Final Year females with refugee parents had extended their learning of global social inequalities in a Baccalaureate course. Two School A, First Year Australian females of South-East Asian background arranged a visit to a remote Indigenous school and became informed of students' social and educational disadvantages. A Final Year female at School A defended social justice as a religious tenet of the Catholic church that prohibits pregnancy termination, but was not informed of the moral complexities of decision-making faced by vulnerable pregnant women. An intersectional female in the same Year group had a service- learning experience in a homeless women's shelter which informed her of 'levels of capacity' or empowerment among homeless women resorting to paid sex work for survival. A Final Year School B female, immigrant from eastern Europe, narrated a formative service- learning experience in the Solomon Islands. She recognised the 
need to educate Islander mothers with low health literacy to rehydrate their sick children; an expectation she had taken for granted. These examples of reality-based experiences brought participants closer to a sociological understanding of how context modifies health care needs.

c. Participants from rural and remote areas of Australia, in closer proximity to Indigenous groups, voiced awareness as recognition [105] of the historical nature of unmet Indigenous health needs. Two International School B First Year males considered Australia's health system mismatched to Indigenous health needs and recommended Chinese medicine an alternative. A School B Final Year male participant witnessed physician racism toward an Indigenous patient; while others found the same sexism, homophobia, and racism exists in medical culture as in Australian society.

d. Examples of transformative learning of equity concepts were uncommon. A Final Year female at School A, of African-Australian identity, went to Africa for service-learning and found corruption in the health system, and poor rural people with low critical consciousness and health literacy. However, street theatre as a means of health education of HIV-AIDS risks provided an example of social accountability fitting the community context. In another example of service design for health equity, a Final Year School B male training in a remote Australian Indigenous community reported a practice he found 'strange'; implying liminal understanding of the threshold concept of health equity. Diabetes was prevalent, turnout at diabetes clinics was poor, and limb amputations common. The hospital provided cold room storage of limbs in respect for the Indigenous spiritual obligation to be buried whole once a diabetic patient dies. This strategy could improve clinic attendance, diabetic management, and reduce need of amputations. Recognition of this social fact was key to problem solving equitable access to diabetic health care.

In overview, the partial knowing of diverse patient needs participants reported can incrementally transform their ontology or 'becoming to know' as a physician. Student experiences of "engaging, exploring, experiencing, emerging, enabling, and evolving" [106] provide an 'ecosystem view of knowledge' that more closely aligns with the dynamic and uncertain nature of health production in contemporary global societies. Critical reflexivity on holistic or multi-system needs of Indigenous peoples was voiced by outsiders with direct experiences in rural communities. A 'becoming to know' framework was complemented by the critical gazes of intersectional participants on practices unfairly distributing health care based on outmoded and stigmatising colonial gazes. Yet, by Final Year some intersectional participants held a stance that placed unrealistic expectations on patients for specialised knowledge and capabilities, such as health statistics and complex self-care. This represented an ellipsis of habitus [107] to a perspective that ignores patient context as a value in clinical reasoning. The participant was a School B Final Year outsider male who was conscious of his age, the need to repay student loans, and attain financial security. Core values of social justice expected from a disadvantaged background had been supplanted by secondary values of self-concern.

\section{Theme 3. The medical practice of social accountability}

Differences in participants' prosocial agency; how integration of medical and social accountability practices was conceptualised, is collated in Figure 3. For many Final Year participants, 'doing both' 
(health care and social accountability) was unthinkable in the overloaded hospital settings where they trained. A female Final Year, School A, insider commented on the number of patients arriving at hospital in a low SES community. "Some of us ask where does it [sic] come from?" This comment exposed a preliminal understanding of the societal error [108]: the preferential funding of specialised hospital-based care over community-based improvements in social, commercial, and cultural health determinants [109]. In contrast, First Year (PA1) understood the societal error from her own experiences in disadvantaged Singapore communities. She met women that assumed breast screening services were only for women with breast cancer; and others that refused necessary medical treatment if attending a clinic deprived their families of subsistence income.

Several participants construed social accountability simply as 'helping people'.

"I think that's the entire reason that a lot of people go into medicine, because we want to help people and I think that's our responsibility to try to do that even when someone doesn't want to change." (School B First Year female)

This comment recognised the social facts for many patients, living lives unconscious of the unfairness of oppressions limiting their freedom, capabilities, and health [110]. Physicians' equity actions can uncover hidden assumptions in order to correct them; assist patients to navigate the health system; and empower their interrogation of social burdens on their lives. This can be effected as a communicative action or 'dialogic praxis'; mutual learning between patient and physician to help each understand the causes of distress, meaning of emotions in relation to lifeworld, and to motivate engagement in social change [111].

The theme of 'ways of seeing and knowing' drew on participants' moral understandings of the intention of A Physician's Charter of medical professionalism. Critical 'awareness' means more than perception of social inequity; it commits professionals to moral actions of justice and care. The concept of a knowledge management system (KMS), as delineated by Sveiby \& Skuthorpe (2006), explains knowledge as 'a capacity to act' [112]; converting an intangible value into tangible outcomes. "I guess at the end of the day, students will be seeing a lot of social disadvantages in society ...and I think the important thing there, is not treating the symptoms but treating the actual problem. It could be stress causing all those issues." [School B intersectional First Year female)

The starting point was acknowledgement of difference.

"Once you listen to someone who might be very different to you, you can start to understand, what? I don't know... just a lot of different things, I guess." (Final Year male, School B).

“You don't have to be an activist, but even in your encounters with Indigenous people within a medicine context; then, just being respectful or be more culturally aware, things like that can have a positive impact" (First Year female, School A). 
The alternative stance, doing nothing and still being paid, was posed ironically by a Final Year male at School B. Money was responsibilized for negative impacts on the profession's reputation, and in reflexive comments on physician complicity in social inequalities.

"Because I'm white, middle-class, living in Australia, in a developed country, I have access to a lot of things... particularly a lot of privilege and you know, I buy a lot of products by people who are not paid enough money, and that is a huge source of inequality that I contribute to" (First Year female, School B).

Drug prescription and drug company influence on professionalism was also problematised.

"It's very much taught, this is how you treat, and it's a medication. It's also easier to give someone a drug or... just kind of, let people be the way they are, because it's hard to change it." (Final Year male, School A)

Yet, there was a tendency to presentism in some participant responses; defined as "the analytic neglect of historical forces shaping" [113] the professional discourse. One implied that social accountability was a specialised skill; and another, the responsibility of social workers. Lack of continuity with patients meant that students did not learn from the course of their illnesses. Past atrocities of medical intervention, lacking proper accountability to the human context, were mentioned by just one insider male, School B participant.

"There's so little time for doctors and students to reflect on these things, there's so many other pressures... the amount of patients you have to get in, get out...no beds, no time for anything." (Final Year female, School A)

Few participants were reflexive of the macro influences of policy and power structures on these downstream processes; nor the hegemony of science and hospital-based practice on students' collective imagination of 'health' [114]. Critical reflexivity on the social gradient of health inequalities [115] was often prompted by service-learning or community-based experiences in underserved settings. Following clinical placement in the Northern Territory, a School B Final Year insider male wondered at his initial perception of Indigenous health being a single entity. A whole world appeared.

"What do you mean they're Indigenous? Are they Pitjanjatjara, or are they like, Larrakia? Or... ?You can't just paint them (different language groups) with one stroke!"

Behavioural education of individual patients to modify 'lifestyle' was viewed as social accountability by participants responding to a 'proximal risk' paradigm of illness. Diet and exercise prescription reflected the health preoccupations of young middle-class women influenced by social media. Yet no account was taken of patients' social distinctions, their emotional and cognitive states, or contextual lifeworld stressors. Advocacy of further education for disadvantaged mothers was suggested by two School A, First Year outsider females, in recognition of this social determinant of health.

A final theme in participant data referred, in two main ways, to a sustainability paradigm of health care. One participant recognised the problem of high staff turnover in remote clinics, and how this 
disadvantaged continuity of care for Indigenous people. Another understood sustainability as providing multi-disciplinary health services for both illness prevention and health care actions.

\section{Social accountability reasoning}

A general finding was a low capability for problematizing the patient's social context in medical problemsolving; to 'take account of' how inequities in societal conditions of living distribute health and alter the physicians' ethical responsibility.

Interview Question 3, on the difficult physician task of motivating behaviour change, was answered more critically by Final Years with training experiences in underserved rural areas. An example was a rural male participant at School B who compared the ideal patient ("well educated and well informed") with others;

"... from a situation where they have to prioritise a hundred different things, and you've just given them another thing to worry about." Yet, an urban, insider male in Final Year at School A (PA6), regarded social justice "a silly idea" that only led to mixed results, arguing only legal justice mattered. He had learned from a general practice mentor that persistent nagging of patients, to lose weight or quit smoking, was eventually successful. An intersectional School B Final Year female considered dietary education essential for all patients, perhaps reflecting her Hindu dharma (way of life). Yet variation in availability and affordability of fresh foods were neglected in her account.

The theme of awareness revealed the majority perspective of social accountability to this question. Awareness was a metaphor for the physician's need to be mindful or reflexive of composite causation [116]; to cast a critical sociological gaze of health inequities in the patient's lifeworld. The awareness theme also lent support to critical consciousness; in Bourdieu's terminology, critical 'recognition' of differences in power ('capitals') between physicians and patients that underpins need for equity reasoning for social accountability. A First Year female at School B argued for mindfulness of patients' social positioning and how this intersects with illness; "I think it goes hand in hand because a lot of the people doctors deal with are not only sick, but are probably in a group that are marginalised in society or face injustice. I think this [The Charter] is highlighting for, um medical professions, how important it is to keep this in mind." [School B First Year female and outsider]

This empathic awareness was lacking in PA6's account of behaviour change as nagging, and the social practice among physicians of labelling patients with low self-efficacy, 'acopic'. The pseudo-Latin neologism 'acopia' is applied to patients who remain in the hospital system after treatment; unable to cope independently at home. A School B Final Year female was confident that due diligence was done to acopic patients' health care, despite the health team's resentment for the added workload. Postcode shaming stereotyped patients by the demographics of their suburban address. In both examples, there was misrecognition [117] of how the patient's free agency may be immobilised by contextual adversity, structured by social and commercial determinants of health. Equity actions, enabled by physicians' symbolic social status, require evaluation of the patient's lifeworld stressors and correction of misperceptions; identification of SDH deficits, social and political advocacy; critical education; and multidisciplinary action plans. 
Interview Question 7, on the apparent paucity of LGBQTI patients in an urban medical practice, also required awareness of how unconscious bias against stigmatised social identities can be co-constructed by patients and physicians. The topic was best answered by participants disclosing LGBQTI status. They reported social anxiety in public; behaviours to avoid the stigmatisation and violence that plagues LGBQTI sexualities; and the stress of self-stigma that primes some to contemplate suicide. Illegality of homosexuality in Singapore society was an additional stressor faced by PA1 and her peers. PA1 narrated exceptional insight to the ways that marginalised social and legal identities were met by prejudicial treatment by physicians in Singapore's health system; the resulting institutional (or structural) harms further impairing their health. These experiences radicalised PA1 and motivated her entry to medicine.

In their replies to Question 7, a majority proposed hypotheses problematising the physician, the practice, or the LGBQTI community. Against pre-study expectations, two Final Years at School B did not recognise this equity dilemma as an important clinical problem; perhaps habituated to the orthodoxy of demand-led medical practice and the biomedical gaze. A School B Final Year male from Canada declared his millennial generation more accepting of homosexuality than prior generations of physicians. A First Year female at School B referred to a lecture on 'men who have sex with men' and regarded a snap association between LGBQTI sexualities and HIV-AIDS the stigmatising factor causing non-attendance at clinic.

In contrast, students that self-identified as LGBQTI remarked how pervasive social anxiety for homophobic violence was unavoidable in their public life. They advised physicians to be aware of how stigma anxiety affected attendance of 'coming-out' LGBQTI youth at health services; to be reflexive of unconscious bias in communicating with LGBQTI patients; avoid stereotyping patients by their identity and health risks; and recognise the high prevalence of poor mental health related to social discrimination.

The final interview question drew on participants' creative imaginations to conceive novel strategies for alleviating common social problems in an Australian rural community. A male from a remote area, in Final Year School B, spoke about youth sports, men's sheds, and a philosophy club in his town. The concept of 'health production' as improving the health of a community was difficult for most participants, a typical response being "Hopefully that's what we're already doing [by treating illness]." Implicit to misrecognition of public health was the capture of students' medical imagination by an individualist paradigm of society.

This discourse, broadcast in both medical education and neoliberal societies, effectively de-politicises and unfairly responsiblizes patients for their poor social situation [118]. First Year participants from backgrounds more proximal to social disadvantage were more likely to responsibilize systemic constraints than individuals. Yet, a Final Year first-in-family outsider at School B clearly held patients selfresponsible for their health despite his own family's hardships. This adaptation to conservative norms of merit or 'desert' can happen in a hidden curriculum as students undergo 'ellipsis of habitus': distortion of habitual responses to a professional logic unreflexive of contextual social facts. Core values of social justice can then give way to personal concerns, which for this student, was pressing financial debts. 


\section{Discussion}

The study heeded the call for use of social science theory in medical education research to relate to "the fate of our times" [119]. Rapid social changes and instability in contemporary societies underline the need for research that guides social change in medical education; to prepare graduates for health problems emergent from a dynamic and turbulent, real world.

The fragmentation and loss of outsider participants' capability to aspire to prosocial medical professionalism represents a loss of valued ethical capital for socially accountable practice. Despite School B's social accountability ethos and outsider students with strong epistemic relations to the SDH, participants' use of equity concepts to bespoke patient contexts often misrecognised the relevance of the patient's meaning-making of adverse social facts to their well-being. Own equity identities did not prevent some participants mis-recognise others' equity needs. The diversity in participants' agency for social accountability corresponded to the three modes delineated by Bandura (2001); "direct personal agency, proxy agency that relies on others to act at one's behest to secure desired outcomes, and collective agency exercised through socially coordinative and interdependent effort" [120].

Deficits in clinical cognition of equity concepts for patient-centred care were common in the study. In the language of threshold concepts this may indicate pre-liminal understanding of health equity [121]. It may also be considered 'knowledge blindness'; misunderstanding of the way knowledge is cumulative, has different strengths, and has emergent properties of its own [122]. In this paradigm, attuned to changing external conditions graduates become creators of new knowledge, not just torch bearers of the known. This may require a deliberate pedagogy comprising a KMS integrating biomedical content and humanist context in clinical reasoning, signalling moral concern for accountability. A well-constructed KMS ensures all relevant data is included in ethical decision making [123]. A suitable candidate for the ethical organisation of pedagogy is Legitimation Code Theory (LCT), derived from developments in linguistic and educational sociology [124]. In LCT pedagogy, objective and subjective knowledge practices contribute impacts to cumulative knowledge building [125].

In accord with research supporting longitudinal integrated curriculum in primary health care training [126], critical insights to the social structuration of illness were best comprehended by participants reflecting on health problems encountered in settings of social inequity. In LCT terms, these trainees had stronger epistemic relations $(E R+)$ to the social production of illness in the communities they served. Their surprised discourses were replete with new knowledge of contextual relevance [SG+] and changed perspectives. Surprise emotions indicated a shift in dispositions, in the manner Bourdieu termed 'ellipsis' of habitus [127].

Here can be discerned a sequence of transformative learning in which stronger relations (ER+) to contextual knowledge (SG+) shifts the knower's identity; their 'becoming to know' as a physician [128]. School A, First Year participant (PA1), with four intersectional equity identities, had the strongest epistemic relation (ER+) to social adversity, and through loss of personal freedoms had become critically conscious of social injustice experienced by others in her society. While PA1 had become a social activist, 
the expected level of physician engagement in social accountability is more modest. Ethical, informed, and effective solutions are needed to meet changing public health needs.

Further development of health equity problem-solving capability can be instructed by modelling the relevance of medical concepts to indigenous contexts using LCT 'semantic waves' (Fig. 6). Patient acceptability of the Indigenous diabetes management solution reported above is an exemplar of this challenge. Other illustrative examples have been published in the New England Journal of Medicine under the heading of Social Medicine. Having students exercise the skills of critical reflexivity on patient contexts and provide a brief sociological analysis in clinical case presentations may integrate equity principles into routine clinical practice.

At the crux of patient-centred social accountability learning is not the SDH per se, but how the SDH produce signs in patients' lifeworlds; and how each organism interprets and makes meaning of its changing world. In biosemiotics, the organism's sign world or 'semiosphere' communicates all it/ she/ he/ they can know of objects in its world [129]. Yet what meaning is made of this data becomes the health dependent step by which predictive actions are framed. Biosemiotics brings the patient's semiosphere into the symptomatology of clinical reasoning. The pandemic of mental distress related to the global COVID-19 pandemic, and to solastalgia, becomes more visible in this account.

'Acopia' attests to a boundary object in the biomedical frame of professionalism; a remnant of cloth cut from the suit of legitimate biomedical care [130]. The profession's advocacy of Australia's National Disability Insurance Scheme would serve justice to the needs of these patients. Acopia unfairly 'responsiblizes' the disabled and is costly to the health system. It deserves more medical education research attention and may serve as a model for medical learning of social accountability.

\section{Conclusions}

\section{An ecosystem of knowledges and knowers}

The need to be mindful of how patients' lifeworld circumstances can produce illness was partially understood by outsider and insider participants from their diverse social stances.

Health professional 'awareness', construed as sociological imagination of inequity, instead requires the habit of critical reflexivity or problematisation of the sociopolitical structuration of diverse patients' health. Involvement of patients and physicians as born knowers, and physician teams as engaged listeners, may assist the co-construction of socially accountable and sustainable practices. In a cybersemiotic paradigm [131], inequity is signified by adverse signs in the patient's lifeworld; and via CAS, recursively re-models andcybernetically (via feedbacks) communicates illness meanings to semiotic mind-body systems. The CAS process acting in contexts of social adversity [132] is dynamic, non-linear, and prolonged. It can exceed the physiological controls that have evolved to maintain internal homeostasis, alter genomic activity, and result in chronic illness. 


\section{Signalling responsibility for justice in medical pedagogy}

The above description of a multi-methods study of medical students' conceptions of socially accountable professionalism revealed diversely layered but uneven aspirations, capabilities, and readiness for social justice practices. There was collective will for social justice learning, and agreement about the major groups disadvantaged in the Australian health care system. The two groups of participants whose capabilities for social accountability need support in medical education were those with nil and multiple equity identities. Participants in close relation to social adversity, and those reflecting on recent situated learning of social facts, were closer in 'becoming to know' [133] social accountability praxis.

Firstly, apart from participants with intersectional equity identities, how contextual knowledge of macro and micro social conditions in a patient's lifeworld modifies the organisation of medical knowledge was poorly systematized in interview responses. This problem compounds the tendency to under-value the 'voice of the lifeworld' in clinical interviewing [134]. Secondly, most intersectional participants chose to follow conventional career paths; and some revealed transformed identities to uncritical practices of medical professionalism. Among these were Final Year participants at School B, studying in a declared socially accountable program. This finding resonates with a study of the market attraction of the legal profession in the U.K. to ethnic and culturally diverse students [135], understood as a social mobility project. Despite being inspired by the social justice ideal, expected gains in financial and symbolic capitals (regardless of their somewhat ambivalent depictions of corporate lawyers) decided participants' choices of a corporate career path.

Single equity identity participants were planning to practice medicine in areas of need and were 'becoming to know' patients' equity needs in clinical and service-learning settings. Motivated First Year females at School A had informed themselves of equity needs in an Indigenous community. Just one intersectional female participant PA1 at School A, and a male at School B (PB4), had embodied knowledge of social inequity that they transferred to other groups facing social inequity.

The 'awareness' theme pointed to reflexivity as the critical logic for equity reasoning.

Reflexivity on how social context modifies health decisions, unlike reflection models of learning, is the ethical habit of problematising science knowledge in relation to humanist knowledge of patients' realities. This 'accounting for' practice acts like a metaphor to create new knowledge or solutions to fundamental causes of health [136]. Reflexivity, also termed super-subjectivity, has abstraction as its logic instead of the inductive/deductive processes of disease diagnosis. The integration of medical and humanist knowledges into a dualistic praxis has been elusive in medical education. However, theories of higher education that link the works of educational sociologists Pierre Bourdieu, Basil Bernstein, and Karl Maton provide a sophisticated guide for educators of practice-related knowledges.

\section{Education of reflexivity on patient context}


Among recommendations for 'tomorrow's doctors' proposed by Parsell \& Bligh (1995), was "introduce integrated and systems-based curricula to eliminate the pre-clinical/ clinical divide" [137]. The results of this study support a radical re-envisioning of the teaching and learning of psychosocial history-taking to prepare graduates to enact social justice in health care and health improvement [138]. Problem-based or case-based learning has been widely employed for systems integration; but arguably, the balance owed to social systems acting in patients' life contexts has been subjugated by a hierarchy of bioscientific concepts. This finding resonates with criticisms of the learning fallacy in medicine, in which the knowledge taught has little relation to its importance in clinical work [139]. Bernstein \& Solomon (1999) studied the linguistic properties of critical education discourses and attributed reflexive learning to shifts between the 'vertical' hierarchy of specialised disciplinary knowledges and 'horizontal' or contingent lifeworld knowledges [140]. The relevance of dual process theories of education to systems thinking arose as 'theory after' the present study [141], emerging from the mixed methods data.

"Symbolic power is the power to make things with words" [142]. The legitimation of specialised discourses in traditional medical pedagogy means that greater power is coded by hierarchical, vertical biomedical discourses than horizontal, lifeworld discourses. In this regard, Brosnan (2013) characterised the significance students hold about determinacy of biomedical science to the quality of medical programs as a 'black box' [143]. This knowledge relativism represents a false dichotomy, and a recognised crisis in education. Karl Maton (2009) noted the existence of symbolic code duality in all disciplinary practices. He created a lexicon for educators categorising hierarchical specialised knowledge, such as biosciences, semantic density (strong = SD+, weak = SD-), and dynamic sociological knowledge of human contexts as semantic gravity (strong = SG+, weak = SG-) [144]. Entry of these dual discourse 'codes' (SD, SG) into a KMS framework can assist educators to signify the relevance of biomedical discourses (SD) to social systems structuring diverse human contexts (SG). Codes, rather than capitals, are the units of linguistic power in pedagogic discourses that direct learners to legitimate social and medical knowledges, and acknowledge the relational strengths of 'knowers' [145]. LCT pedagogic practice effectively models reflexivity on contexts and engages patient and student diversity in knowledge democracy; from which creative and socially accountable knowledge practices can emerge. It signals a shift in physician investigations from 'what is the matter, to what matters' [146].

LCT can assist educators to achieve equity of learning outcomes with students of diverse social backgrounds [147]. Best practice in LCT entails weaving cumulative and segmental knowledge discourses in 'semantic waves' [148] (Figure 6, below); to build conceptual knowledge and direct the learner's gaze to relevant social knowledges. Health equity discourses modify biomedical concepts to match disadvantaged patient contexts, such as Indigenous health. LCT may assist students to problematise the contextual differences between Indigenous and non-Indigenous peoples, in addition to gaps in health outcomes. Educators need to become familiar with horizontal knowledge of equity groups, such as cultural norms, and employ code shifts accordingly. Students in close relation to the systems structuring Indigenous health have legitimate social knowledges that can leverage semantic gravity (SG+, SG-). In LCT, axiology (values), epistemology (knowledges) and semantic communication (meanings) can legitimise medical professional responsibilities for social accountability. Medical educators can involve 
consenting student or patient perspectives, their critical recognitions, and misrecognitions, and use LCT to adjust semantic wave arrays in accord with learning evaluations [149].

Figure 6. Concepts of low semantic gravity (SG-) or low relation to patient context, and concepts of high semantic density (SD+) such as hierarchical biomedical knowledge, are progressively 'unpacked' or clarified by reference to high semantic gravity and low semantic density precepts. This practice legitimates significant patient contexts (such as high equity needs), and low semantic density (SD-) or lay medical discourses. As an example, teaching about breast cancer, the facilitator can stress the importance of checking women's health literacy apropos the value of breast screening; their freedom to attend clinics; transport; child-minding needs; personal concerns; and disabling myths. In LCT pedagogy, concepts are tabled by the educator to ensure all relevant topics are covered, examined, and evaluated.

The mapping of codes may effectively re-contextualise the medical professional ethos, although this needs testing in longitudinal studies. Joining the metaphysical 'map to the territory' aims to eliminate disciplinary 'knowledge blindness' [150]. In Fig. 7, this is denoted by the sociological topics in the shaded area of the circle. In medical education of 'society', educators need to regard knowledge and the operation of epistemic reflexivity as serious objects of study; for students to overcome the societal error [151]. The latter refers to misrecognition of the body as the sole locus of health production, that instead requires mitigation of social and commercial health determinants. This error was exemplified in the study by a School A Final Year insider participant reflecting on the hectic downstream hospital context, wondering 'where they all come from?' Insight to this knowledge enigma can be coded in medical pedagogy; and effect curricular justice to the graduates who enter the public health system. The social realist thesis Maton (2010) promotes directs educators to create more powerful forms of knowledge and to "enable them to be more accessible to everyone" [152].

In LCT, semiotic principles organise pedagogy enabling educators to recontextualise [153] clinical discourses to validate systemic causes of health inequity. The biosemiotic paradigm of science [154] may complement LCT, to convey the dialogical relations linking societal conditions and human wellbeing; from which functional meanings are cybernetically interpreted as health or illness [155]. Outsiders' diverse equity identities encode stance or relation to social inequities that can direct peers' gazes to contextual social facts; and cultivate sociological imagination of health as a professional norm. This is "the idea of a communicative teaching in which the teachers and learners together participate in the creation of common meaning" [156]. The concern with inadequate 'curricular justice' to outsider students, 'knowers' with latent dispositions for social health, is the negative transformation of prosocial values to the dominant biomedical model. The result may be loss of critical insights and agency for social health improvements, fractured physician habitus [157], and medicalisation of psychosomatic conditions.

The participants most capable of epistemic reflexivity in clinical reasoning of Questions $3 \&$ 7. had social equity identities and sociological gazes informed by strong epistemic relations (ER+) to contexts of social inequity. Females had strongest vocational interest in practicing medicine in an underserved community; and, while those with high intersectionality chose to avoid this career path they can bring 'funds of 
knowledge' of social contexts to group learning [158]. Prosocial insiders with weak epistemic relations (ER-) to SDH may be powerful allies in producing socially accountable actions; but some need to critically distinguish between patients' meaning-making of charity versus empowerment actions.

There were participants in all study cohorts that denied the relevance of social identification of patients. Some argued this history item was unnecessary or inappropriate. Yet socially accountable practice includes anticipation of how social inequity in a patient's lifeworld signifies or 'communicates' chronic illness [159]. Anticipatory care and justice are medical professional competencies for early intervention of common community health problems including depression, hypertension, diabetes, cancers, and HIV/AIDS. Knowledge of the patient's social equity identity (Indigenous, LGBQTI, etc.) becomes a medical indexical sign for allopathic stress load, illness vulnerability, and equity needs [160]. (See Figure 7 , above.)

Psychosomatic illness, including conversion disorder, may accompany medical illness. [161] Clinical educators may need to coach students' understanding of liminal concepts of social justice when learning history-taking; and to appreciate how stigma and self-stigma modify the sensitivity of doctor-patient communications. Standardised patients and knowers can add authenticity to this learning.

A proposed second step of social accountability is enquiry into which SDH predominate in the patient's lifeworld. Significant lifeworld signs, such as strong memories primed by past trauma of detention, may make conditions of pandemic lockdown more salient to refugees. Thirdly, information technology solutions are needed that assist medical teams to report, collate and coordinate 'upstream' actions on the sociopolitical geography of health. Actions at the political level can be supported by a 'health-in-allpolicies' approach to government [162].

Meta-reflexivity on global inequities, and how they may impact diverse patient lifeworlds were not clearly articulated. There was no specific question about global health inequities, yet some participants had experienced family displacement and solastalgia: anxiety related to global warming. Several participants were members of the climate health activism group Doctors for the Environment Australia. Absent from participants' global discourses were other health-related ecosocial contexts, displacement of human populations, land clearing, species extinction, and environmental toxins.

Further research may be helpful to clarify the socialisation of prosocial capitals in health professions student-led groups. Further studies are recommended to explore the intentions and career paths of medical students that choose Type F. professionalism, 'Follow your own morality, what works for you' [163]. This is assisted in Australia by a database tracking graduates' projected career path, and factors in choice of preferred area of medicine. In 2019, the selection of 'alignment with personal values' was second only to 'atmosphere/

work culture of the discipline' [164]. Yet the percentage of graduates choosing to work in Australia's underserved rural areas was falling. Collaboration with, and empowerment of, equity groups may pay dividends in both upstream and downstream health settings. A more enlightened view of social inclusion 
regards higher education a resource for groups and communities to access in pursuit of collective aspirations [165].

Future-facing professionalism may require physicians to reflexively apply critical sociological imagination to manage emerging local and global ecosocial crises that re-distribute health equity needs. Meanings abstracted in biosemiotics point to functions that professionals can apply in ethics [166], education [167, 168], and medical care [169] to get students thinking about health and illness outside the biomedical 'black box'. Investigation of the immaterial relations of bodies to human contexts may have more to offer health outcomes than the material relations of biomedicine can know [170].

For more information on Legitimation Code Theory: www.legitimationcodetheory.com

\section{Abbreviations}

LGBQTI: lesbian, gay, bisexual, queer, transsexual and intersex

MCQ: multiple choice question

SAQ: short answer question

SES: socio-economic status

HIV-AIDS: human immunodeficiency virus - acquired immunodeficiency syndrome

CAS: complex adaptive systems

NCD: non-communicable disease

KMS: knowledge management system

LCT: Legitimation Code Theory

SD: semantic density

SG: semantic gravity

SDH: social determinants of health

\section{Declarations}

\section{Ethics approval and consent to participate.}

All methods were carried out in accordance with ethical guidelines set by Flinders Social and Behavioural Research Ethics Committee (Approval \#6877) on 1 July 2015 and approval was granted by the Ethics 
Committee of the Research and Evaluation Expert Reference Group for a mixed methods study of medical students. An approved consent form was signed by each participant before the study commenced.

Consent for publication. Not applicable.

Data availability. The datasets generatedand analysed during the current study are available fromDrK $\mathrm{J}$ Whittenbury E: kingsley.whittenbury@flinders.edu.au

Competing interests. The author declares he has no competing interests.

Funding. PhD study

Author contributions. Dr K J Whittenbury wrote all drafts of the article.

\section{Acknowledgements.}

Dr Paul R Ward, Professor of Public Health, College of Medicine \& Public Health, Flinders University (primary supervisor) Contact: paul.ward@flinders.edu.au

Dr David Hunter, Senior Lecturer in Medical Ethics. University of Adelaide (secondary supervisor) Contact: david.hunter@adelaide.edu.au

Dr Lisa Davies assisted with editing.

\section{Author's information.}

Kingsley James Whittenbury graduated in Medicine from The University of Adelaide in 1978.

He practiced primary health care in remote regions of Australia for 22 years and began a lectureship in medical professionalism at The University of Adelaide medical school in 2004. He completed a PhD at Flinders University College of Medicine \& Public Health in 2021, and is now an independent academic with interests in biosemiotics, edusemiotics \& semioethics.

ORCID: https://orcid.org/0000-0002-3871-0433

Contact details: kingsley.whittenbury@gmail.com

\section{References}

1. Mennin S. Complexity and health professions education. J of Evaluation in Clinical Practice 2010; 16:835-837 doi:10.1111/j.1365-2010.01502.x

2. Parsell GJ, Bligh J. The changing context of undergraduate medicine. Postgrad Med $J$ 1995;71;837:397-403 Available at https://doi.org/10.1136/pgmj.71.837.397 
3. ABIM. Medical professionalism in the new millennium: A physician's charter. Lancet2002;359:52022 doi: 10.7326/0003-4819-136-3-200202050-00012

4. Kumagai AK, Lypson ML. Beyond cultural competence: critical consciousness, social justice, and multicultural education. Academic Medicine2009; 84;6:782-78 doi: 10.1097/ACM.0b013e3181a42398

5. Medical Professionalism Project. Medical professionalism in the new millennium: A physician's charter. Lancet2002;359:520-22 doi: 10.7326/0003-4819-136-3-200202050-00012

6. Reay D. Habitus and the psychosocial: Bourdieu with feelings.Cambridge J Education 2015;45;1:9-23 (p20) http://dx.doi.org/10.1080/0305764X.2014.990420

7. Brosnan $\mathrm{C}$ et al. Experiences of medical students who are first in family to attend university. Medical Education2016;50:842-851 doi: 10.1111/medu.12995

8. Nicholson S \& Cleland JA. "It's making contacts": notions of social capital and implications for widening access to medical education. Adv in Health Sci Educ2017;22:447-490 doi: $10.1007 /$ s10459-016-9735-0

9. Bleakley et al. Chapter 4. Socio-cultural learning theories. Medical education for the future. Advances in Medical Education 1.Springer; 2011. doi: 10.1007/978-90-481-9692-0_4

10. Benatar SR. Moral imagination: the missing component in global health. PLoS Medicine2005;2;12:e400 Available at https://doi.org/10.1371/journal.pmed.0020400

11. Bezemer J. Social semiotics: theorising meaning making. D. Nestel et al. (Eds.) Clinical Education for the Health Professions. Singapore: Springer Nature; 2020. (p2) Available at: https://doi.org/10.1007/978-981-13-6106-7_26-1

12. Charter on Medical Professionalism. Annals of Internal Medicine 2002;136; 3:243-246

13. Marmot $\mathrm{M}$ et al. Working for Health Equity: The role of health professionals. Executive Summary. London: UCL Institute of Health Equity; 2013.

14. Baum FE. The new public health. Fourth Ed. OUP; 2016.

15. Marmot M. The health gap: doctors and the social determinants of health. Scandinavian J of Public Health 2017;45:686-693 doi: 10.1177/1403494817717448

16. Westerhaus M, Finnegan A, Haidar M, Kleinman A, Mukherjee J \& Farmer P. The necessity of social medicine in medical education. Acad Med2015;90; 5:565-568 doi: 10.1097/ACM.0000000000000571

17. Madaras L, Stonington S, Seda CH, Garcia D \& Zuroweste E. Social distance and mobility - A 39 year old pregnant farmworker. N Engl J Med 2019;380; 12:1093-1096 doi: 10.1056/NEJMp181150116

18. Baum FE, Begin M, Houweling TAJ \& Taylor S. Changes not for the faint-hearted: reorienting health systems toward health equity through action on the social determinants of health. Am J Public Health2009;99;11:1967-1974 doi: 10.2105/AJPH.2008.154856

19. Waitzkin H. A critical theory of medical discourse: ideology, social control and the processing of social context in medical encounters. J Health and Social Behaviour 1989;30; 2:220-239 doi: $10.2307 / 2137015$ 
20. Bourdieu P. Outline of a theory of practice. Cambridge Studies in Social Anthropology; 1977.

21. Jureidini J, McHenry LB. The illusion of evidence-based medicine. Exposing the crisis of credibility in medical research.South Australia: Wakefield Press; 2020.

22. Hafferty FW, Castellani B. The increasing complexities of professionalism. Acad Med2010; 85;2:288301

23. Bleakley A, Bligh J \& Browne J. Medical education for the future. Identity, power and location. In Hamstra SJ. (Ed.). Advances in Medical Education, Volume 1. Springer; 2011. (p.246)

24. Bourdieu P. Outline of a theory of practice. Cambridge Studies in Social Anthropology; 1977.

25. Brosnan $C$ et al. Experiences of medical students who are first in family to attend university. Medical Education2016;50:842-851 doi: 10.1111/medu.12995

26. Crandall SJS, Reboussin BA, Michielutte R, Anthony JE \& Naughton MJ. Medical students' attitudes to underserved patients: a longitudinal comparison of problem-based and traditional medical curricula. Advances in Health Sciences Education 2007;12:721-86 doi: 10.1007/s10459-005-2297-1

27. Becker HS, Geer B. The fate of idealism in medical school. Harvard Educational Review 1958;28:7080 Available at doi: $10.2307 / 2088623$

28. Kaplan RM. Behavior change and reducing health disparities. Preventive Medicine2014; 68:5-10 Available at: htpp://dx.doi.org/10.1016/j.ypmed.2014.04.014

29. Kauffman SA. At home in the universe. The search for the laws of self-organization and complexity.New York: Oxford University Press; 1995.

30. Aretz HT. Some thoughts about creating health professionals that match what societies need. Med Teach2011;33;8:608-613 Available at http://dx.doi.org/10.1136/jme.18.3.148

31. Brosnan C. Making sense of differences between medical schools through Bourdieu's concept of field. Medical Education 2010;44:645-652 doi: 10/1111/j.1365-2923.2010.03680.x

32. Brosnan $\mathrm{C}$. Why and how social science theory can contribute to medical education research. Medical Education 2013; 47:3-17 doi: 10.1111/medu.12093

33. Curlin FA, Dugdale LS, Lantos JD \& Chin MH. Do religious physicians disproportionately care for the underserved? Ann Fam Med 2007;5:353-360

34. Prideaux D, Lindemann I, Cottrell A. Community and workplace expectation of graduates in the health professions. Ch 7. in, Educating health professionals: becoming a university teacher. Loftus S, Gerzina T, Higgs J, Smith M \& Duffy E. (Eds.) Rotterdam/ Boston/ Taipei: Sense; 2013.

35. Lave J, Wenger E. Communities of practice: Learning, meaning, and identity. Cambridge University Press; 1998.

36. Reay D. Habitus and the psychosocial: Bourdieu with feelings.Cambridge J Education 2015;45; 1:923 (p20) Available at http://dx.doi.org/10.1080/0305764X.2014.990420

37. Evans K. Concepts of bounded agency in education, work and the personal lives of young adults. International J Psychology 2007;47;2:85-93 (p88). doi: 10.1080/00207590600991237 
38. Allen D, Wainwright M, Mount $B$ \& Hutchinson T. The wounding path to becoming healers: medical students' apprenticeship experiences. Med Teach 2008;30:260-264 doi:

10.1080/01421590701758665

39. Archer M. The reflexive imperative in late modernity. UK: Cambridge; 2012.

40. Zipin L, Sellar S, Brennan M \& Gale T. Educating for futures in marginalized regions: a sociological framework for rethinking and researching aspirations. Educational Philosophy and Theory 2015;47;3:227-246 Available at https://doi.org/10.1080/00131857.2013.839376

41. Maton K \& Moore R. (Eds). Social realism, knowledge and the sociology of education. Coalitions of the mind. London: Continuum Books; 2010.

42. Freire P. Pedagogy for critical consciousness. New York: Seabury Press; 1973.

43. Mustakova-Possardt E. Education for critical moral consciousness. J Moral Education2004;13;3:245269 Available at: https://doi.org/10.1080/0305724042000733046

44. Kickbusch I, Allen L \& Franz C. The commercial determinants of health. Lancet2016; 4:e895 Available at https://doi.org/10.1016/S2214-109X(16)30217-0

45. Thomas AJ, Barrie R, Brunner $\mathrm{J}$ et al. Assessing critical consciousness in youth and young adults. $\mathrm{J}$ of Research on Adolescence2014;24;3:485-496 doi:10.1111/jora.12132

46. Baum FE. The new public health. Fourth Ed. OUP; 2016.

47. Therborn G. The killing fields of inequality. Cambridge, UK: Polity Press; 2013.

48. Kull K, Emmeche C \& Favereau D. Biosemiotic questions. Biosemiotics 2008;1: 41-55 doi: $10.1007 /$ s12304-008-9008-2

49. von Uexküll J. An introduction to Umwelt. Semiotica2001;134;1:107-110

50. Hoffmeyer J. Biosemiotics: an examination into the life of signs and the signs of life.Scranton, Philadelphia: Uni of Scranton Press; 2008.

51. Tredinnick-Rowe J. Can semiotics be used to drive paradigm changes in medical education? Sign Systems Studies2018; 46; 4:491-516 Available at: https://doi.org/10.12697/SSS.2018.46.4.05

52. Brier $\mathrm{S}$. The cybersemiotic paradigm of communication: an evolutionary view on the threshold between semiosis and informational exchange. tripleC2003;1;1:71-94 Available at: http://tripleC.uti.at

53. Hoffmeyer J. Biosemiotics: an examination into the life of signs and the signs of life.Scranton, Philadelphia: Uni of Scranton Press; 2008.

54. Elwood TW. Viewing health care through a semiotic veil of signs. J of Allied Health 2012; 41;1:1-13

55. Rafieian S. A biosemiotic approach to the problem of structure and agency. Biosemiotics 2012; 5:8393 doi: 10.1007/s12304-9121-5

56. Smith KE \& Pollak SD. Early life stress and development: potential mechanisms for adverse outcomes. J of Neurodevelopmental Disorders 2020;12:34 Available at https://doi.org/10.1186/s11689-020-09337-y

57. Wheeler W. Expecting the earth. Life, culture, biosemiotics. London: Lawrence \& Wishart; 2016. 
58. Hills J, Lees J, Freshwater D \& Cahill J. Psychosoma in crisis: an autoethnographic study of medically unexplained symptoms and their diverse contexts. British $\mathrm{J}$ of Guidance andCounselling 2016;46:135-147 Available at: https://doi.org/10.1080/03069885.2016.1172201

59. Sen A. Development as freedom. New York: Alfred A. Knopf; 1999.

60. Bourdieu P. Outline of a theory of practice. Cambridge Studies in Social Anthropology; 1977.

61. Marmot MG, Rose G, Shipley M \& Hamilton PJS. Employment grade and coronary heart disease in British civil servants. J Epidemiol Community Health1978;32:244-249 Available at doi: 10.1136/jech.32.4.244

62. Hart CS. Aspirations, education and social justice: applying Sen and Bourdieu. Bloomsbury Publishing; 2003.

63. Wear D, Aultman JM. (Eds.). Professionalism in medicine. Critical perspectives. Springer; 2006.

64. Bernstein B. Pedagogy, symbolic control and identity.London: Taylor \& Francis; 1996.

65. Kull K, Velmezova E. Jesper Hoffmeyer: biosemiotics is a discovery. Biosemiotics2019; 12:373-379 Retrieved from: https://doi.org/10.1007/s12304-019-09367-7

66. Bourdieu P. Distinction: A social critique of the judgment of taste. London: Routledge; 1984.

67. Wharton AS. (1999). The psychosocial consequences of emotional labour. ANNALS of the American Academy of Political and Social Science 561:158-176 Retrieved from: https://doi.org/10.1177/000271629956100111

68. Maton K \& Moore R. (eds). Social realism, knowledge and the sociology of education. Coalitions of the mind. London: Continuum Books; 2010.

69. Edwards G. (2014). Standpoint theory, realism and the search for objectivity in the sociology of education. British J Soc Ed35;2:167-184 Available at http://dx.doi.org/10.1018/01425692.2012.747588

70. Bogue R \& Semetsky I. Reading signs/ learning from experience: Deleuze's pedagogy as becomingother. Chapter 8. In Semetsky I. (ed.) Semiotics, Education, Experience. Rotterdam/Boston/Taipei: Sense Publishers; 2010.

71. Hoffmeyer J. Biosemiotics: an examination into the life of signs and the signs of life.Philadelphia: Uni of Scranton Press; 2008.

72. Campbell C. Educating semiosis: foundational concepts for an ecological edusemiotic. Studies in Philosophy and Education2019;38:291-317 (p291) Available at https://doi.org/10.1007/s11217-0189617-4

73. Hatzenbuehler ML, Link BG. Introduction to the special issue on structural stigma and health. Social Science \& Medicine2014;103:1-6 doi:10.1016/j.socscimed.2013.12.017

74. Anderson MR, Smith L \& Sidel VW. What is social medicine? Monthly Review 2005; 8: 27-34. (p31) Available at https://doi.org/10.14452/MR-056-08-2005-01_3

75. Kull K. Umwelt and modelling. In: Cobley P. (ed.) The Routledge Companion to Semiotics. London: Routledge, 2010. 
76. Crenshaw K. Mapping the margins. Stanford Law Review 1993; 43:1241-99 doi: 10.2307/1229039

77. Bernstein B. Pedagogy, symbolic control and identity. London: Taylor \& Francis; 1996.

78. Hafferty FW. Beyond curriculum reform: confronting medicine's hidden curriculum. Academic Medicine1998; 73; 4:403-407 doi: 10.1097/00001888-199804000-00013

79. Ward PR. The relevance of equity in health care for primary care: creating and sustaining a fair go for a fair innings. Quality in Primary Care2009;17:49-54

80. Bourdieu P, Wacquant LJD. An invitation to reflexive sociology. University of Chicago: Polity Press; 1992.

81. Sommerlad $\mathrm{H}$. Researching and theorizing the processes of professional identity formation. $\mathrm{J}$ of Law and Society 2007;34; 2:190-21 (p.195) Available at https://doi.org/10.1111/j.14676478.2007.00388.x

82. Brosnan C. Pierre Bourdieu and the theory of medical education. Thinking 'relationally' about medical students and medical curricula. In C Brosnan \& BS Turner (Eds.) Handbook of the sociology of medical education. Taylor \& Francis eBook; 2009.

83. Griffin B, Porteli E \& Hu W. Who do you think you are? Medical student socioeconomic status and intention to work in underserved areas. Adv in Health Sci Educ2017; 22:491-504 doi: 10.1007/s10459-016-9726-1

84. Bernstein B. Pedagogy, symbolic control and identity. London: Taylor \& Francis; 1996.

85. Castellani B, Hafferty FW. The complexities of medical professionalism: a preliminary investigation. In Wear D, Aultman JM. (Eds.). Professionalism in medicine. Critical perspectives. Springer; 2006. (p9)

86. American Board of Internal Medicine. The Physician Charter. Available from: https://abimfoundation.org/what-we-do/physician-charter Accessed 19/11/21

87. Langer PC. The research vignette: reflexive writing as interpretive representation of qualitative inquiry - a methodological proposition. Qualitative Inquiry 2016; 22; 9:735-744 Available at: https://doi.org/10.1177/1077800416658066

88. Bourdieu P. Outline of a theory of practice. Cambridge Studies in Social Anthropology, 1977.

89. Bernstein B, Solomon J. Pedagogy, identity and the construction of a theory of symbolic control. British J of Sociology of Education 1999; 20;2:265-279

90. Meyer J, Land R. Threshold concepts and troublesome knowledge: linkages to ways of thinking and practising within the disciplines. Higher Education2005;49:373-388 doi: 10.1007/s10734-004-6779-5

91. Therborn G. The killing fields of inequality. Cambridge, UK: Polity Press; 2013.

92. Meyer $S \&$ Ward P. 'How to' use social theory within and throughout qualitative research in healthcare contexts. Sociology Compass 2014:525-539 Available at https://doi.org/10.1111/soc4.12155

93. Rawls J. A theory of justice. Cambridge: Harvard University Press; 1971.

94. Wear D, Aultman JM. (Eds.). Professionalism in medicine. Critical perspectives. Springer; 2006. 
95. Langer PC. The research vignette: reflexive writing as interpretive representation of qualitative inquiry - a methodological proposition. Qualitative Inquiry 2016;22;9:735-744 Available at: https://doi.org/10.1177/1077800416658066

96. Denzin NK. Triangulation 2.0. J Mixed Methods Research 2012;6;2:80-88 Available at https://doi.org/10.1177/1558689812437186

97. Seale C, Gobo G, Gubrium JF \& Silverman D. Qualitative Research Practice. London: SAGE; 2004.

98. Savransky M, Rosengarten M. What is nature capable of? Evidence, ontology and speculative humanities. Medical Humanities2016;0:1-7 doi:101136/medhum-2015-010858

99. Meyer S \& Ward P. 'How to' use social theory within and throughout qualitative research in healthcare contexts. Sociology Compass 2014:525-539 Available at https://doi.org/10.1111/soc4.12155

100. Mizrahi T. Getting rid of patients: contradictions in the socialization of physicians. New Brunswick: NJ Rutgers University Press; 1986.

101. Beagan BL. Neutralizing differences: producing neutral doctors for (almost) neutral patients. Social Science \& Medicine2000; 51:1253-1265 doi: 10.1016/S0277-9536(00)00043-5

102. Savransky M, Rosengarten M. What is nature capable of? Evidence, ontology and speculative humanities. Medical Humanities2016; 0:1-7 doi:101136/medhum-2015-010858

103. Nöth W. The semiotics of teaching and the teaching of semiotics. (p.5) Chapter 1. In, Semetsky I. (Ed.) Semiotics education experience.Rotterdam/ Boston/ Taipei: Sense Publishers; 2010.

104. Frenk J, Chen L, Bhutto Z, Cohen J, et al. Health professionals for a new century: transforming education to strengthen health systems in an interdependent world. The Lancet 2010;376:1923-58 (p.1952) doi: 10.1016/S0140-6736(10)61854-5

105. Bourdieu P \& Wacquant LJD. An invitation to reflexive sociology.University of Chicago: Polity Press; 1992.

106. Jakubik M. Becoming to know. Shifting the knowledge creation paradigm. J of Knowledge Management2011;15;3:374-402 (p374.) Available at doi:10.1108/13673271111137394

107. Bourdieu P. Outline of a theory of practice. Cambridge Studies in Social Anthropology; 1977.

108. Stone JR. Saving and ignoring lives: physicians' obligations to address root social influences on health - moral justifications and educational implications. Cambridge Quarterly of Healthcare Ethics2010;19:497-509 Available at doi: 10.1017/S0963180110000393

109. Baum FE, Begin M, Houweling TAJ \& Taylor S. Changes not for the faint-hearted: reorienting health systems toward health equity through action on the social determinants of health. Am J Public Health2009;99;11:1967-1974 doi: 10.2105/AJPH.2008.154856

110. Freire P. Pedagogy for critical consciousness. New York: Seabury Press; 1973.

111. Béhague DP, Frankfurter RG, Hansen H \& Victora CG. Dialogical praxis - a 16 year old boy with anxiety in Southern Brazil. N Engl J Med2020;382;3:201-204 doi: 10.1056/NEJMp1909864

112. Sveiby K-E, Skuthorpe T. Treading lightly: the hidden wisdom of the world's oldest people. Australia: Allen \& Unwin; 2006. (p.176) 
113. Rimke H. Sickening Institutions: a feminist, sociological analysis and critique of religion, medicine and psychiatry. (p19) Chapter 2. In Kilty JM, Dej E. (Eds.) Containing Madness. Springer; 2018. Available at https://doi.org/10.1007/978-3-319-89749-3_2

114. Brosnan C. The significance of scientific capital in UK medical education. Minerva 2011;49;3:317-332 doi: 10.1007/s11024-011-9177-z

115. Marmot $M$ et al. Working for Health Equity: The role of health professionals. Executive Summary. London: UCL Institute of Health Equity; 2013.

116. McLaren G. Health in an ecological civilisation: towards a process understanding of the dialectics of health. Cosmos \& History: The Journal of Natural and Social Philosophy2019; 15; 1:427-484 Available at http://www.cosmosandhistory.org/index.php//journal/article/view/773

117. Bourdieu P \& Wacquant LJD. An invitation to reflexive sociology.University of Chicago: Polity Press; 1992.

118. Grunwald K \& Thiersch H. The concept of the 'lifeworld orientation' for social work and social care. J of Social Work Practice2009; 23; 2:131-146 Available at https://doi.org/10.1080/02650530902923643

119. Brosnan C. How and why social science theory can contribute to medical education research. Medical Education 2013;47:3-17 (p6.) doi: 10.1111/medu.12093

120. Bandura A. Social learning theory. USA: General Learning Corporation; 1971. (p.2)

121. Meyer J, Land R. Threshold concepts and troublesome knowledge: linkages to ways of thinking and practising within the disciplines. Higher Education2005; 49:373-388 doi: 10.1007/s10734-004-6779-5

122. Maton K. Knowledge and knowers: towards a realist sociology of education. Routledge; 2013.

123. Sveiby K-E, Skuthorpe T. Treading lightly: the hidden wisdom of the world's oldest people. Australia: Allen \& Unwin; 2006.

124. Maton K \& Moore R. (Eds). Social realism, knowledge and the sociology of education. Coalitions of the mind. London: Continuum Books; 2010.

125. Wilmot K, McKenna S. Putting knowledge at the centre: the uptake of Legitimation Code Theory in higher education studies in South Africa. In Huisman J \& Tight M. (Eds.) Theory and Method in Higher Education Research. Emerald; 2021.

126. Hirsh D, Walters L \& Poncelet AN. Better learning, better doctors, better delivery system: possibilities from a case study of longitudinal integrated clerkships. Medical Teacher 2012;34:548-554 doi: $10.3109 / 0142159 \times .2012 .696745$

127. Bourdieu P. Outline of a theory of practice. Cambridge Studies in Social Anthropology; 1977.

128. Jakubik M. Becoming to know. Shifting the knowledge creation paradigm. J of Knowledge Management2011;15;3:374-402 doi:10.1108/13673271111137394

129. Semetsky I. (Ed.) Semiotics education experience. Netherlands: Sense Publishers; 2010.

130. Star SL. This is not a boundary object: reflections on the origin of a concept. Science, Technology \& Human Values2010;35;5:601-617 
131. Bayliss EA, Bonds DE, Boyd CM, Finke B, et al. Understanding the context of health for persons with multiple chronic conditions: moving from what is the matter to what matters. Ann Fam Med 2014:260-269 doi: 10.1370/afm.1643 Accessed 21/11/21

132. Brier $\mathrm{S}$. The cybersemiotic paradigm of communication: an evolutionary view on the threshold between semiosis and informational exchange. tripleC2003; 1; 1:71-94 Available at: http://tripleC.uti.atJ

133. Jakubik M. Becoming to know. Shifting the knowledge creation paradigm. J of Knowledge Management 2011;15; 3:374-402 doi:10.1108/13673271111137394

134. Barry CA, Stevenson FA, Britten N, Barber N, Bradley CP. Giving voice to the lifeworld. More humane, more effective medical care? A qualitative study of doctor-patient communication in general practice. Social Science \& Medicine 2001;53:487-505

135. Sommerlad H. Researching and theorizing the processes of professional identity formation. $\mathrm{J}$ of Law and Society 2007;34; 2:190-21 (p.195) Available at https://doi.org/10.1111/j.14676478.2007.00388.x

136. Kumagai AK, Lypson ML. Beyond cultural competence: critical consciousness, social justice, and multicultural education. Academic Medicine 2009; 84;6:782-78 Available at doi: 10.1097/ACM.0b013e3181a42398

137. Parsell GJ, Bligh J. The changing context of undergraduate medicine. Postgrad Med J1995;71;397403 (p399). Available at https://doi.org/10.1136/pgmj.71.837.397

138. Bernstein B, Solomon J. Pedagogy, identity and the construction of a theory of symbolic control. British J of Sociology of Education 1999;20; 2:265-279

139. Nilsson S. On the meaning of higher education in professional practice: the case of physicians and engineers. J Education and Work 2010;23;3:255-274 doi: 10.1080/13639080.2010.486397

140. Bourdieu P. Social space and symbolic power. Sociological Theory 1989;7; 1:14-25 (p.23).

141. Meyer S \& Ward P. 'How to' use social theory within and throughout qualitative research in healthcare contexts. Sociology Compass2014:525-539 Available at https://doi.org/10.1111/soc4.12155

142. Maton K. Cumulative and segmented learning: exploring the role of curriculum structures in knowledge-building. Br. J Sociol Educ2009; 30:43-57 doi: 10.1080/01425690802514342

143. Brosnan C. The significance of scientific capital in UK medical education. Minerva2011;49; 3:317-332 doi: 10.1007/s11024-011-9177-z

144. Maton K, Moore R. (Eds). Social realism, knowledge and the sociology of education. Coalitions of the mind. London \& New York: Continuum; 2010.

145. Winberg C, McKenna \& Wilmot K. (Eds.) Building knowledge in higher education. Enhancing teaching and learning with Legitimation Control Theory. London and New York: Routledge; 2021.

146. Bayliss EA, Bonds DE, Boyd CM, Finke B, et al. Understanding the context of health for persons with multiple chronic conditions: moving from what is the matter to what matters. Ann Fam Med 2014:260-269 doi: 10.1370/afm.1643 Accessed 21/11/21 
147. Winberg C, McKenna \& Wilmot K. (Eds.) Building knowledge in higher education. Enhancing teaching and learning with Legitimation Control Theory. London and New York: Routledge; 2021.

148. Maton K. Making semantic waves: a key to cumulative knowledge-building.Linguistics and Education2013;24:8-22 Available at https://dx.doi.org/10.1016/j.linged.2012.11.005

149. Maton K, Hood S, Shay S. (Eds.) Knowledge Building: Educational Studies in Legitimation Code Theory. Abingdon and New York: Routledge; 2016.

150. Maton K. Knowledge and knowers: towards a realist sociology of education. Routledge; 2014.

151. Stone JR. Saving and ignoring lives: physicians' obligations to address root social influences on health - moral justifications and educational implications. Cambridge Quarterly of Healthcare Ethics2010; 19:497-509 doi: 10.1017/S0963180110000393

152. Maton K \& Moore R. (Eds). Social realism, knowledge and the sociology of education. Coalitions of the mind. London: Continuum Books; 2010. (p.10)

153. Bernstein B. Pedagogy, symbolic control and identity. London: Taylor and Francis; 1996.

154. Hoffmeyer J. A biosemiotic approach to the question of meaning. Zygon2010;45; 2:367-390

155. Brier S. The cybersemiotic paradigm of communication: an evolutionary view on the threshold between semiosis and informational exchange. tripleC2003;1;1:71-94 Available at: http://tripleC.uti.at

156. Huttunen R. Indoctrination, communicative teaching and recognition - studies in critical theory and democracy in education. University of Joensuu; 2009. Publications in Education no. 131. (p.vi).

157. Bourdieu P \& Wacquant LJD. An invitation to reflexive sociology. University of Chicago: Polity Press; 1992.

158. Zipin L, Sellar S, Brennan M \& Gale T. Educating for futures in marginalized regions: a sociological framework for rethinking and researching aspirations. Educational Philosophy and Theory 2015;47;3:227-246 Available at https://doi.org/10.1080/00131857.2013.839376

159. Campbell C. Educating semiosis: foundational concepts for an ecological edusemiotic. Studies in Philosophy and Education 2019;38:291-317 (p.291) Available at: https://doi.org/10.1007/s11217018-9617-4

160. Rimke H. Introduction - mental and emotional distress as a social justice issue: beyond psychocentrism. Studies in Social Justice2016;10;1:4-17

161. Tossani E \& Fava GA. Psychosomatic approach to clinical practice. In Koh KB. (Ed.) Somatization and psychosomatic symptoms. New York: Springer Science + Business Media; 2013. doi: 10.1007/978-1-4614-7119-6_7

162. Kickbusch I, Williams C \& Lawless A. Making the most of open windows: establishing health in all policies in South Australia. International J of Health Services 2014;44;1:185-194 Available at http://dx.doi.org/10.2190/HS.44.1.k

163. Wear D \& Aultman JM. (Eds.) Professionalism in medicine. Critical perspectives. Springer; 2006.

164. Medical Schools Outcome Database. National Data Report; 2020. (Table 24.) Available at https://medicaldeans.org.au/md/2020/08/2020-MSOD-National-Data-Report_2015-2019-Full- 
report.pdf

165. Sellar S, Gale T \& Parker S. Appreciating aspirations in Australian higher education. Cambridge J Education2011;41;1:37-52 Available at https://doi.org/10.1080/0305764X.2010.549457

166. Petrilli S. Sign studies and semioethics: communication, translation and values. Berlin/ Boston: De Gruyter; 2014.

167. Deely J, Semetsky I. Semiotics, edusemiotics and the culture of education. Educational Philosophy and Theory2017;49;3:207-219 doi: 10.1080/00131857.2016.1190265

168. Maton K. Making semantic waves: a key to cumulative knowledge-building.Linguistics and Education 2013;24:8-22 Available at https://dx.doi.org/10.1016/j.linged.2012.11.005]

169. Tredinnick-Rowe J. Can semiotics be used to drive paradigm changes in medical education? Sign Systems Studies 2018;46; 4:491-516 Available at: https://doi.org/10.12697/SSS.2018.46.4.05

170. Wheeler W. Expecting the earth. Life, culture, biosemiotics. London: Lawrence \& Wishart; 2016. (p.257)

\section{Tables}

Table 1.

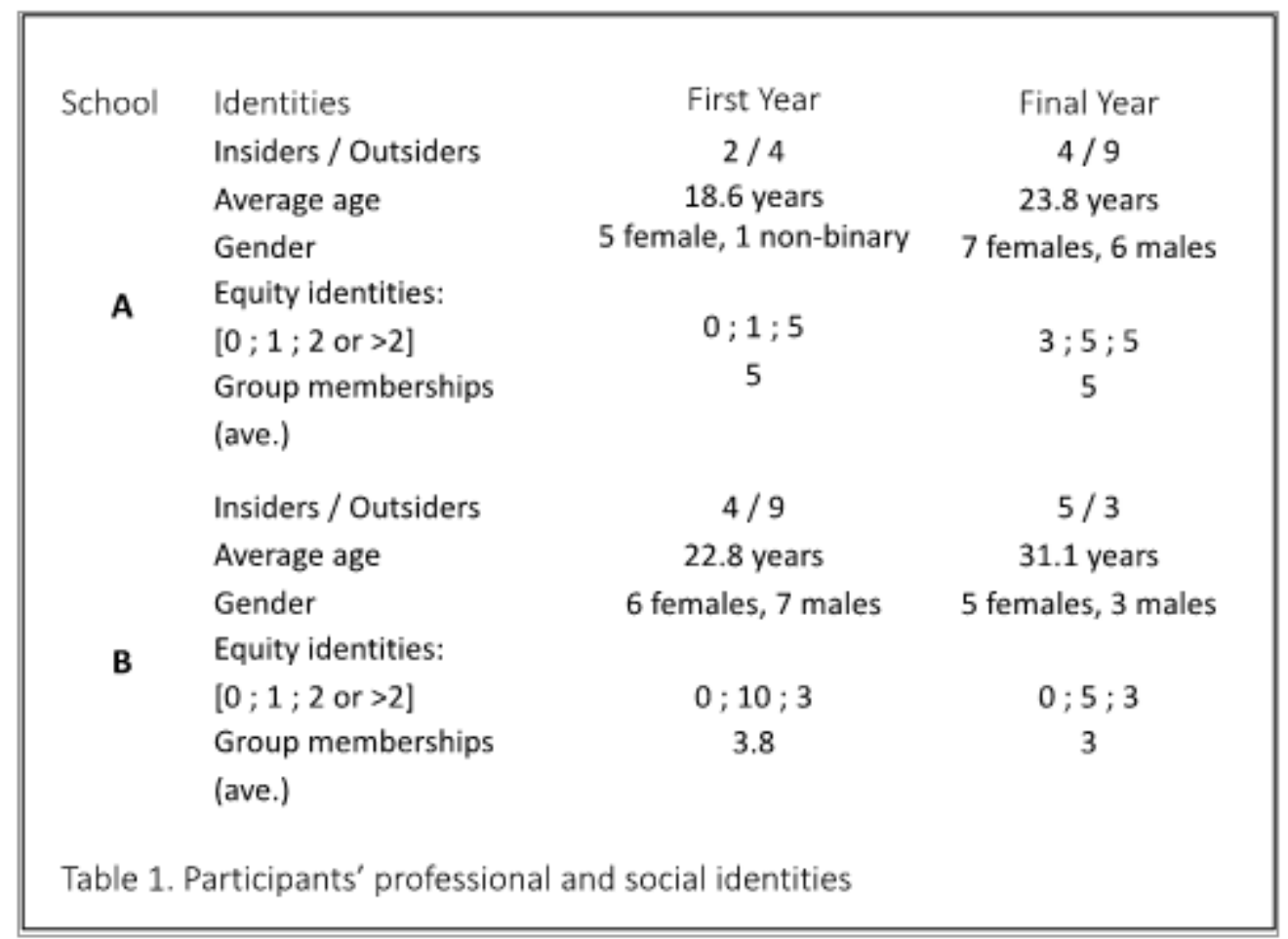

\section{Figures}



Stronger
Weaker
knower gazes
knower gazes

Borngaze Socialgaze Cultivated gaze Trained gaze

Fig 1. Knower grammars and gazes

Maton 2010, Fig. 8.2 p.166, with permission. [41]

Figure 1

See image above for figure legend

Figure 2. Interview Questions discussed in text.

\section{Interview Q3.}

Many doctors experience 'learned helplessness' when treating people who continue to engage in unhealthy behaviours despite receiving good advice for keeping healthy.

What is your perspective of this problem?

What are the fundamental causes of this problem?

\section{Interview Q7.}

An Capital City general practitioner knows that about $10 \%$ of the population is homosexual, but she is not aware of any homosexual patients in her practice.

What could be the problem and what could she do to change the situation?

Figure 2 
Figure 3.

Number of social equity identities \& choice of Type G. professionalism (percent) Types of medical professionalism

Nil

One

Two or more

$11.1 \%$

The percentage of *single equity identity participants choosing to practice in an area of need was almost twice that of participants with either nil or two or more equity identities.

$11.1 \%$

$21.1 \%$
(Castellani \& Hafferty 2006) [63]

A. Traditional doctor, working long hours, dedicated to patients

B. Medical practice as a means to business ventures

C. Combine medical practice with teaching and research

D. Part-time doctor, part-time other interests e.g. family, lifestyle

E. Technical mastery, specialist, financial success

F. Follow your own personal morality, what works for you

G. Practice in an area of need, concern for disadvantaged groups

Figure 3

See image above for figure legend 
Figure 4. Scope of participants' concerns for social justice and health care.

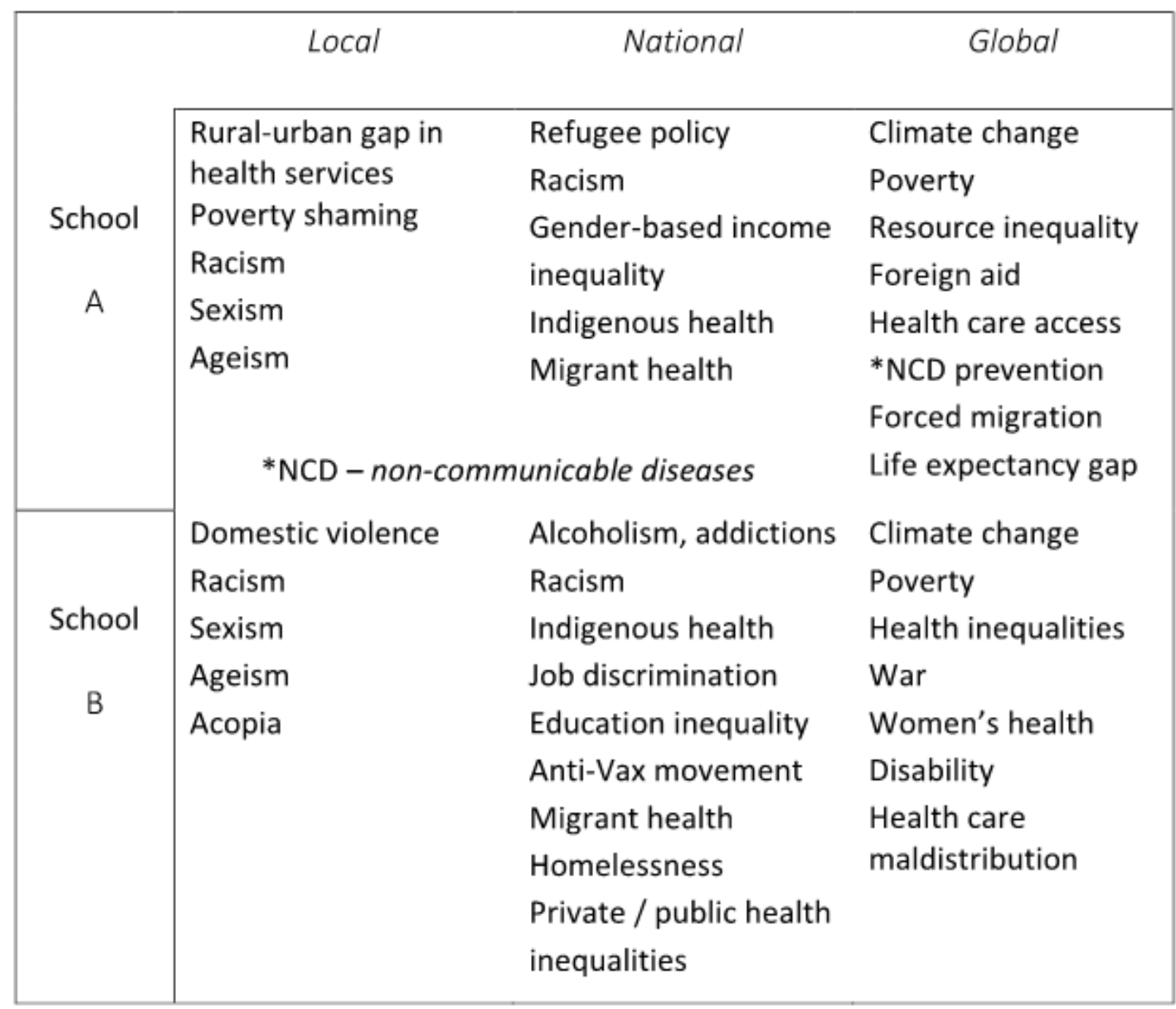

Figure 4

See image above for figure legend 
Figure 5. Themes and subthemes of interview discourses

1. Critiques of contemporary medical professionalism

2. Transformation to a social justice perspective of medical practice

2A. Informative learning

2B. Formative learning

2C. Transformative learning

3. The medical practice of social accountability

3A. Responses to The Charter

3B. Awareness

3C. Agency differences; helping patients

3D. Ways of 'seeing' and knowing

3E. Space-time for social accountability practices

3F. Education to overcome health inequities

3G. Sustainability

$3 \mathrm{H}$. Conscious boundaries of social accountability

Figure 5

See image above for figure legend 
Figure 6. Semantic wave diagram (from Maton 2013:15 Fig. 4)

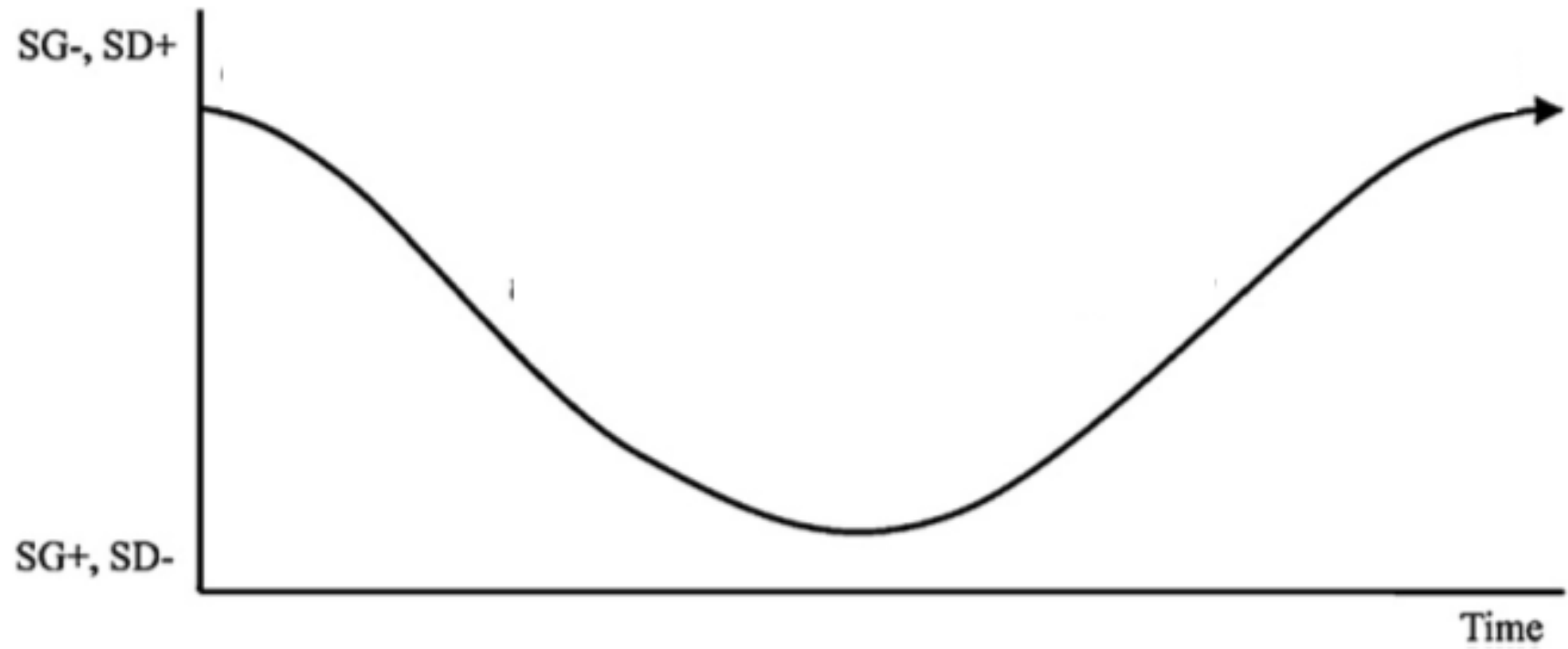

Figure 6

See image above for figure legend

Figure 7. Extended signs and knowledges relevant to health outcomes

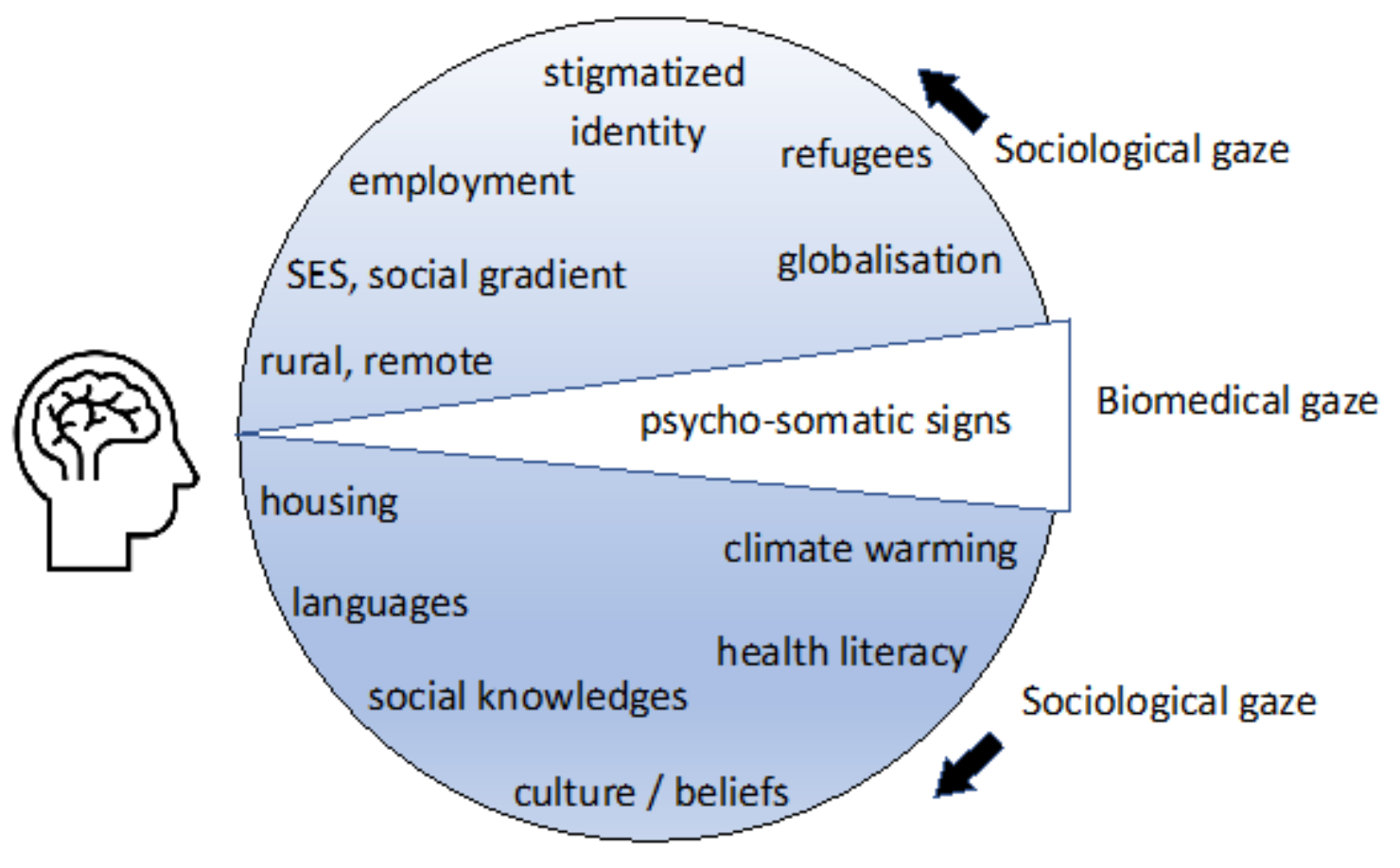


Figure 7

See image above for figure legend 